\title{
Determinantes do Comportamento Particularista de Legisladores Estaduais Brasileiros*
}

\author{
Mônica Mata Machado de Castro \\ Fátima Anastasia \\ Felipe Nunes
}

\author{
“Todos os deputados do Congresso têm como primeiro \\ interesse serem reeleitos. Alguns deputados não têm outro \\ interesse" (Frank E. Smith apud Mayhew, 1974; \\ tradução dos autores) $)^{1}$.
}

\section{INTRODUÇÃO}

$\mathrm{O}$ tema central deste artigo é a representação política em doze Casas Legislativas dos estados de Rio Grande do Sul, Santa Catarina, São Paulo, Minas Gerais, Rio de Janeiro, Goiás, Mato Grosso, Bahia, Pernambuco, Ceará, Tocantins e Pará. O objetivo é analisar os efeitos: (a) das dinâmicas da competição política; (b) da filiação partidária dos deputados, considerando o posicionamento ideológico de seus parti-

\footnotetext{
* Esta é a quarta versão, bastante modificada, de trabalho apresentado originalmente no Grupo de Estudos Legislativos da Associação Nacional de Pós-Graduação e Pesquisa em Ciências Sociais (Anpocs), em outubro de 2008, e no ISeminário Federalismo, Descentralização e Políticas Públicas no Brasil, promovido pela Fundação Luís Eduardo Magalhães (Flem) e pela Universidade Federal da Bahia (UFBA), em Salvador, em dezembro de 2008. Agradecemos as críticas e sugestões de Fabiano Santos, Lúcio Rennó, Magna Inácio e dos estudantes do Programa de Pós-Graduação em Ciência Política da Universidade Federal de Minas Gerais (UFMG) que cursaram a disciplina Legislativos Subnacionais em Perspectiva Comparada, ministrada pelas professoras Fátima Anastasia e Magna Inácio no segundo semestre de 2008. Agradecemos, especialmente, os comentários e as críticas dos pareceristas anônimos da revista DADOS.
}

DADOS - Revista de Ciências Sociais, Rio de Janeiro, Vol. 52, n-4, 2009, pp. 961 a 1001. 
dos; (c) dos tipos de apoiadores consistentes; e (d) de bases eleitorais sobre o comportamento legislativo dos deputados investigados.

São utilizados os resultados produzidos na pesquisa Trajetórias, Perfis e Padrões de Interação das Elites Estaduais Brasileiras, desenvolvida pelo Centro de Estudos Legislativos do Departamento de Ciência Política da Universidade Federal de Minas Gerais (CEL-DCP-UFMG) ${ }^{2}$. Entre os meses de setembro de 2007 e fevereiro de 2008, foi aplicado um questionário com o objetivo de coletar informações a respeito dos parlamentares daquelas Casas Legislativas; dos 624 deputados que constituíam o universo, 513 participaram da investigação ${ }^{3}$. Como não foi construída uma amostra representativa desse universo, não se pretende, nesta análise, fazer inferências para o conjunto dos deputados estaduais brasileiros. O objetivo é examinar se certas proposições teóricas se sustentam quando contrastadas com os dados coletados ${ }^{4}$.

Além das informações obtidas por meio do survey, foram levantadas e sistematizadas aquelas sobre os sistemas partidários estaduais, as coalizões eleitorais e os resultados do pleito de 2006 para a distribuição das vagas nas Assembleias Legislativas e para os governos dos estados da Federação.

O projeto de pesquisa chamou a atenção para a carência de estudos sobre os legislativos subnacionais no Brasil e, especialmente, para a necessidade de realizar análises comparadas, longitudinais e transversais que contribuam para o acúmulo de conhecimento sobre o comportamento, o processo e a produção legislativa no âmbito dos estados federados. Seguindo sugestão de Loewenberg (2008), acredita-se que trabalhos dessa natureza podem contribuir para o desenvolvimento de uma teoria geral sobre o funcionamento de Casas Legislativas. Afirma-se no referido projeto:

Nos últimos anos, coincidindo com o processo de estabilização política, houve um enorme incremento da produção acadêmica sobre a democracia brasileira, seus atributos e seu funcionamento. Quem quer que esteja acompanhando tal produção pode presenciar um rico debate em torno de como se governa o Brasil.

Nesse processo, os mais diversos temas têm chamado a atenção dos pesquisadores [...] (Abranches, 1988; Ames, 2003; Anastasia e Melo, 2002; Anastasia, Melo e Santos, 2004; Avelar e Cintra, 2002; Carvalho, 2003; Cheibub, Figueiredo e Limongi, 2002; Figueiredo e Limongi, 1999; 2002; Mainwaring, 1993; 2001; Melo, 2004; Melo e Anastasia, 2005; 
Nicolau, 2002; Samuels, 2003; Santos, 2003; Soares e Rennó, 2006; Vianna, 2002).

No entanto, a produção acima mencionada, em sua maioria, tem se voltado para o exame do sistema político brasileiro na sua esfera nacional, contando-se, em bem menor número, os estudos até agora realizados cujo foco esteja voltado para as unidades subnacionais. Ainda mais rarefeita é a produção que busca comparar o quadro encontrado em tais unidades, sejam elas estaduais ou municipais.

Foi Lima Júnior (1983) quem primeiro chamou a atenção, na ciência política brasileira, para a necessidade de que se levasse às últimas consequências o fato de que o Brasil é uma república federada. A organização federativa do país, mais ainda após 1988, faz com que os recursos disponíveis nos planos estadual e municipal sejam capazes de alimentar dinâmicas políticas próprias, as quais se refletem, por exemplo, em subsistemas partidários ou em padrões de carreira e de produção legislativa bastante diferenciados. Mais recentemente, trabalho organizado por Santos (2001) representou a primeira tentativa de realização de estudos de caso tendo como objeto de análise o Poder Legislativo em alguns estados da federação.

Ainda é, portanto, bastante incipiente o conhecimento produzido sobre os legisladores estaduais e suas interações com os cidadãos e com os líderes de coalizões (Arnold, 1990). A pesquisa em tela propôs-se, exatamente, a contribuir para o preenchimento dessa lacuna por meio da análise comparada das condições e das instituições sob as quais se desenvolve a competição política nos diferentes estados. Investigouse, entre outras dimensões, o contexto decisório em que atuam os legisladores, especialmente o formato dos sistemas partidário eleitoral e parlamentar, a correlação de forças políticas em cada estado, a conformação das bases eleitorais e os tipos de apoiadores consistentes, segundo a percepção dos próprios deputados. Procurou-se averiguar os efeitos desses fatores sobre o comportamento político, classificado em termos do grau de particularismo versus universalismo que caracteriza a atuação dos deputados na arena legislativa.

A análise multivariada foi a ferramenta utilizada para testar os impactos combinados das variáveis independentes sobre o comportamento dos deputados.

Este artigo apresenta, inicialmente, o esquema analítico e as hipóteses do trabalho. Propõe-se, a seguir, a operacionalização da variável inde- 
pendente "competição política" e a classificação dos subsistemas estaduais nessa dimensão, de acordo com a sugestão de Lima Júnior (1983). Na seção seguinte, informa-se sobre a medida das outras variáveis independentes propostas acima; segue-se a operacionalização da variável dependente "grau de comportamento particularista dos deputados estaduais entrevistados". Procede-se, então, ao teste das hipóteses, por meio de análise multivariada. Finalmente, é realizado um esforço de interpretação dos resultados encontrados.

\section{O ESQUEMA ANALÍTICO}

Seguindo o percurso analítico trilhado pela literatura especializada, o pressuposto central desta investigação é o de que os legisladores são atores racionais, orientados para fins. As explicações informadas pela noção de conexão eleitoral afirmam que o principal objetivo perseguido pelos legisladores é o de sua reeleição (Mayhew, 1974; Fenno, 1973). Em Congressmen in Committees, Fenno afirma que os legisladores procuram realizar três metas, sendo a primeira delas a reeleição, seguida pela busca de poder no interior do Congresso e pela produção de boa política pública (1973:1). Mayhew define os legisladores como atores que têm na reeleição seu maior objetivo (1974:5), embora reconheça que eles possam perseguir outras metas relacionadas e não necessariamente incompatíveis com esse objetivo (ibidem:16) ${ }^{5}$.

Vale, no entanto, ressaltar especificidades que recobrem a análise do comportamento dos deputados no Brasil. Em contraste com os colegas norte-americanos, cuja principal meta é a reeleição, a ambição dos parlamentares brasileiros é mais dinâmica, envolvendo diferentes percursos e trajetos que têm por fim maximizar as chances de sucesso políti$\mathrm{co}$, ainda que em diferentes arenas (legislativa e executiva) ou em diferentes cargos (eletivos e não eletivos) ${ }^{6}$.

Os argumentos de Fenno e de Mayhew inauguraram uma instigante agenda de pesquisa relativa aos determinantes do comportamento legislativo, com ênfase nos fatores exógenos (características dos sistemas eleitoral e partidário; conexão eleitoral) e endógenos (regras formais que informam as interações dos legisladores) às Casas Legislativas. Tal agenda desembocou, entre outras veredas, nos três conhecidos modelos de organização legislativa: distributivista (Mayhew, 1974), informacional (Krehbiel, 1990) e partidário (Cox e McCubbins, 2005), cada qual postulando um tipo de associação entre as regras que distri- 
buem direitos, recursos e atribuições parlamentares entre os legisladores e seu comportamento na arena legislativa. Nos três modelos, os legisladores buscam maximizar suas chances de reeleição, mas em cada um deles as regras formais do jogo afetam de formas diferentes a probabilidade de consecução de tais fins, tendo em vista as diferentes condições institucionais para a produção de ganhos de troca ou de informação ${ }^{7}$. Assim, a predominância do comportamento particularista dos legisladores (caracterizado pela produção de benefícios concentrados e de custos dispersos) seria esperada no contexto de vigência do modelo distributivista, por contraste com a prevalência do comportamento universalista, compatível com os modelos partidário e informacional.

Outra importante contribuição registrada na literatura foi dada por Arnold (1990), que se propôs a explicar, com uma única teoria, o triunfo de cada um de três interesses em competição: geral, grupal e geográfico, mostrando por que o mesmo deputado ora escolhe políticas voltadas para a produção de interesses gerais, ora escolhe políticas voltadas para a produção de interesses grupais ou de bases geográficas. Em suas palavras: "A teoria nem sempre prediz um único resultado. Meu objetivo, portanto, é mostrar como os cálculos eleitorais formatam todo o comportamento dos atores políticos, desde as decisões em votações nominais às estratégias e táticas de líderes de coalizão"8 (Arnold, 1990:5-6; tradução dos autores).

Partindo da análise dos cálculos, ações e interações de cidadãos, legisladores e líderes de coalizões, sua teoria explica a variação no comportamento de um mesmo legislador durante seu mandato. Segundo Arnold, quando têm de tomar uma decisão, os legisladores se perguntam, em primeiro lugar, qual das alternativas em competição contribui mais para suas chances de reeleição. Sob essa perspectiva, para tomar uma decisão, o legislador precisa: (a) identificar todos os públicos atentos e desatentos que podem se preocupar com a questão em pauta; (b) estimar a direção e a intensidade de suas preferências (reais e potenciais); (c) estimar a probabilidade de as preferências potenciais serem transformadas em preferências reais; (d) pesar todas essas preferências de acordo com o tamanho dos vários públicos atentos e desatentos; e (e) dar um peso especial às preferências de seus apoiadores consistentes (ibidem:82).

Nesse sentido, Arnold (ibidem) possibilita que seja feita uma distinção importante entre as bases eleitorais dos legisladores e seus apoiadores 
consistentes. Base eleitoral refere-se à dimensão espacial da distribuição dos votos dos parlamentares. Assim, os legisladores podem ser caracterizados por diferentes tipos de base, a depender do padrão de sua votação: regional, segmentado ou universal. Os apoiadores consistentes, por sua vez, são os atores decisivos para a campanha eleitoral do parlamentar; são aqueles que sustentam a candidatura do deputado, podendo assumir o papel de formadores de opinião, articuladores de apoio coletivo na sociedade e de financiadores de campanha. Na política brasileira, os principais apoiadores consistentes que um deputado estadual pode ter são prefeitos, vereadores, deputados federais, senadores, empresários, líderes comunitários ou sindicais, religiosos, professores e comunicadores de massa. Essa diferenciação remete à possibilidade de que um parlamentar venha a ter base eleitoral de um tipo e apoiadores consistentes de outro.

Vale sublinhar os ganhos analíticos produzidos por Arnold ao explorar, em uma única teoria, os efeitos combinados dos padrões de interação entre legisladores, cidadãos e líderes de coalizão e das regras e estratégias procedimentais disponíveis para os legisladores em cada contexto institucional em que eles interagem.

A partir da teoria proposta por Arnold, é possível investigar a variação de comportamento entre os legisladores em um mesmo contexto decisório e explicar por que, em uma mesma votação, alguns escolhem alternativas voltadas para a produção de interesses gerais e outros, alternativas voltadas para a produção de interesses grupais ou geográficos.

O enfrentamento dessa questão remete o argumento de volta para Mayhew e para a necessidade de revisitar a explicação do comportamento informado pela conexão eleitoral. Mayhew elencou as diferentes atividades a que se dedicam os legisladores, visando maximizar suas chances de sucesso nas urnas: advertising, credit claiming e position taking (1974:49-77). Tais atividades são direcionadas a cimentar suas interações com seus eleitores e colher votos. Ele já mencionava, no entanto, a necessidade de distinguir analiticamente o eleitorado em geral dos atores políticos relevantes. Um ator político relevante é definido como "[...] alguém que tem recursos que poderiam ser usados na eleição em questão. Nas urnas, os únicos recursos utilizáveis são os votos, mas há recursos que podem ser traduzidos em votos: dinheiro, habilidade de persuasão, habilidade de organização etc. ${ }^{\prime 9}$ (ibidem:39; tradução dos autores). 
As três atividades assinaladas por Mayhew - advertising, credit claiming e position taking - relacionam-se, de forma complexa, com o foco da explicação de Arnold, referente à produção de políticas voltadas para o interesse geral, grupal ou geográfico e, especialmente, com a ênfase conferida pelo autor à consideração, pelos legisladores, das preferências de seus apoiadores consistentes.

Propõe-se, aqui, examinar, em primeiro lugar, se as variáveis de contexto elencadas pela literatura como variáveis independentes, especialmente o "grau de competição política nos diferentes estados da Federação", implicam variação no grau de particularismo do comportamento dos deputados ${ }^{10}$. Em segundo lugar, propõe-se verificar se: (1) a filiação partidária dos deputados, considerando o posicionamento ideológico de seus partidos; (2) os tipos de apoiadores consistentes; e (3) os tipos de base eleitoral são atributos dos legisladores que constituem explicação robusta para as variações no comportamento legislativo dos parlamentares, também tomados individualmente.

Vale assinalar que a primeira variável independente - "competição política nos estados" - é de natureza contextual e, portanto, distinta das demais variáveis que se referem ao legislador individual.

As hipóteses a serem testadas, portanto, são as seguintes:

H1: quanto maior a competição política estadual, menor o grau de comportamento particularista ${ }^{11}$;

$\mathrm{H} 2$ : deputados tenderão a se comportar de forma particularista quanto mais à direita estiver o partido ao qual é filiado, quanto mais regional for o perfil de seus apoiadores consistentes e quanto mais suas bases eleitorais forem de tipo regional.

\section{Variável Independente I: Competição Política}

A operacionalização da variável independente, "grau de competição política estadual", foi proposta a partir de um diálogo com Lima Júnior (1983), referente a seu estudo dos subsistemas partidários estaduais da democracia de 1946. O autor classificou os subsistemas partidários brasileiros, no período de 1945 a 1962, utilizando especialmente dois indicadores de competitividade: o número médio de partidos efetivos e a fragmentação eleitoral média nas eleições legislativas estaduais do período. Neste artigo, propõe-se classificar os casos analisados por meio de dois índices, o de competição eleitoral e o de competição 
legislativa, que levam em conta uma série de variáveis, além das utilizadas por Lima Júnior.

A decisão de medir o conceito de competição política por meio da construção desses dois índices está informada pela percepção de que é logicamente plausível a existência de diferentes combinações entre competição eleitoral e competição legislativa nos diversos contextos (os doze estados da Federação investigados) ${ }^{12}$.

Os índices para expressar a competição política foram construídos levando-se em conta três dimensões consideradas relevantes na literatura:

a) a dimensão governo versus oposição;

b) a dimensão ideológica (esquerda versus direita);

c) o grau de dispersão das forças políticas.

Em relação à primeira dimensão, considera-se que: 1) com referência à competição eleitoral, quanto maior a proporção de votos obtidos por partidos que não participaram da coligação eleitoral vitoriosa para o governo dos estados, maior o grau de competição política estadual; 2) com referência à competição legislativa, quanto maior a proporção de deputados que afirmam se aproximar da oposição ao governo, maior é o grau de competição política estadual. Na segunda dimensão, supõe-se que: 1) quanto maior a distância ideológica entre o partido do governador eleito e a média das posições dos partidos da principal coligação de oposição que concorreu ao governo dos estados, maior a competição política estadual; 2) quanto maior o grau de polarização ideológica dos partidos que compõem as Assembleias Legislativas, maior é o grau de competição política estadual. Considera-se ainda que graus maiores de dispersão das forças políticas no processo eleitoral e nas Casas Legislativas indicam também mais competição política estadual.

Assim, para a construção do índice de competição eleitoral (ICE) foram utilizados os seguintes indicadores:

(a) na dimensão governo versus oposição, calculou-se a proporção de votos dados aos candidatos a deputado estadual, pertencentes a partidos que não participavam da coligação vitoriosa para o governo dos estados, sobre o total de votos válidos na eleição legislativa estadual de $2006^{13}$. 
(b) na dimensão esquerda versus direita, utilizou-se uma adaptação do índice de distância ideológica de Sani e Sartori (1980). Os autores propuseram, como medida de distância ideológica entre dois partidos, a diferença entre as posições de cada um deles na escala de direita versus esquerda, dividida pela diferença máxima possível, que é de nove (9), uma vez que a escala varia de um (1) a dez (10). Aqui, interessa utilizar a medida como indicador da distância entre as duas principais forças políticas em competição na arena eleitoral. Dessa forma, calculou-se o seguinte índice:

$D I=\left|\frac{P_{p 1}-\overline{P_{c p 2}}}{9}\right|$

Em que $D I$ = distância ideológica;

$P_{p 1}=$ posição ideológica do partido do governador eleito;

$P_{c p 2}=$ média da posição ideológica dos partidos que compuseram a coligação eleitoral que ficou em segundo lugar (no primeiro ou no segundo turnos), em cada um dos estados da Federação, na eleição de 2006.

O índice de distância ideológica pode variar de zero (0) - situação que ocorreria na ausência de diferença entre a posição ideológica do partido do governador eleito e a média da posição dos partidos da coligação que ficou em segundo lugar - a um (1) - situação em que as duas posições acima ocupam os extremos na escala ideológica de direita versus esquerda.

A medida da posição ideológica dos partidos políticos no eixo esquerda versus direita foi feita a partir das respostas dadas pelos entrevistados a três perguntas incluídas no questionário: sua autoclassificação na escala que varia de um (1) - esquerda - a dez (10) - direita, a posição que atribuiu ao próprio partido e a avaliação feita sobre outros partidos, na mesma escala - nesse caso, só foram considerados os oito maiores partidos do país (PP*, PDT, PT, PTB, PMDB, DEM, PSB, PSDB e PR). Calculou-se a média dos dois ou três números - no caso dos maiores partidos - resultantes das respostas médias dadas pelos deputados e, dessa forma, os partidos políticos foram distribuídos na escala que, empiricamente, variou de 1,38, para o PC do B, a 7,33, para o DEM ${ }^{14}$.

* Ver lista de siglas dos partidos políticos, com os respectivos significados, no final deste artigo. 
Os números resultantes parecem medir de forma bastante aceitável e coerente a posição ideológica dos partidos políticos brasileiros considerados na análise, levando-se em conta a tendência, já conhecida, de os políticos brasileiros utilizarem raramente, para se localizarem na escala, as posições mais extremas à direita ${ }^{15}$.

(c) como indicador da dispersão das forças políticas nos estados, utilizou-se o índice de fragmentação eleitoral proposto por Rae $(1971)^{16}$. Esse indicador leva em conta a distribuição das proporções de votos obtidos pelos partidos que apresentaram candidatos para o cargo de deputado estadual e o número de partidos em competição. Pode variar de zero (0) - situação em que um partido teria obtido todos os votos - a um (1) - se todos os partidos tivessem o mesmo número de votos ${ }^{17}$.

O ICE apresentado no Quadro 1 foi calculado por meio da soma dos três indicadores acima, que foram padronizados para terem o mesmo peso no índice ${ }^{18}$. Dessa maneira, ele varia de zero, o mínimo de competição, a três, situação de competição máxima. Os estados investigados foram ordenados do menor ao maior valor. É importante lembrar que os dados a respeito 1) da proporção de votos da coligação de oposição ao governador eleito e 2) da fragmentação eleitoral se referem às eleições de 2006, mas o segundo indicador, distância ideológica, foi calcu-

Quadro 1

Índice de Competição Eleitoral Estadual (2006)

\begin{tabular}{|l|c|c|c|c|}
\hline Estado & $\begin{array}{c}\text { Oposição } \\
\text { (padronizada) }\end{array}$ & $\begin{array}{c}\text { Distância Ideoló- } \\
\text { gica (padronizada) }\end{array}$ & $\begin{array}{c}\text { Fragmentação } \\
\text { (padronizada) }\end{array}$ & ICE \\
\hline Santa Catarina & 0,29 & 0,02 & 0,12 & 0,44 \\
\hline Rio de Janeiro & 0,54 & 0,07 & 0,31 & 0,92 \\
\hline Ceará & 0,53 & 0,54 & 0,00 & 1,07 \\
\hline Goiás & 0,41 & 0,34 & 0,35 & 1,11 \\
\hline São Paulo & 0,57 & 0,46 & 0,08 & 1,11 \\
\hline Tocantins & 0,58 & 0,00 & 0,69 & 1,26 \\
\hline Minas Gerais & 0,44 & 0,52 & 0,42 & 1,38 \\
\hline Mato Grosso & 0,00 & 0,46 & 0,06 & 1,46 \\
\hline Bahia & 0,77 & 0,92 & 0,88 & 1,75 \\
\hline Pernambuco & 0,90 & 0,39 & 0,56 & 2,17 \\
\hline Pará & 1,00 & 0,78 & 0,83 & 2,80 \\
\hline Rio Grande do Sul & 0,97 & 1,00 & 2,34 \\
\hline
\end{tabular}

Fonte: TSE (2009); survey Elites Políticas - CEL-DCP (2008). 
lado levando-se em conta também as respostas dadas pelos entrevistados na pesquisa realizada em 2007 e em 2008.

Pode-se observar variação entre os estados quanto ao grau de competição eleitoral, pelo menos no contexto do pleito de 2006. A posição na escala que resultou do índice contrapôs, de um lado, os estados de Santa Catarina, Rio de Janeiro e Ceará, que apresentam menor competição eleitoral, aos estados de Pernambuco, Pará e Rio Grande do Sul, com mais competição eleitoral. O índice indica variedade nos subsistemas políticos estaduais brasileiros, sugerindo que esse fator pode ser importante para explicar outros traços do processo político estadual.

Para medir o grau de competição parlamentar, foi construído o índice de competição legislativa (ICL), utilizando-se os seguintes indicadores:

(a) Na dimensão governo versus oposição, considerou-se a proporção dos deputados que, em cada um dos estados, posicionou-se como de oposição. Esse indicador resultou de pergunta, incluída no questionário, em que se pedia para o deputado se autoclassificar em uma escala de um (1) a dez (10), em que 1 indicava "máxima aproximação do governo" e 10, "máxima aproximação da oposição". A partir da observação das distribuições de frequência dessa variável em cada um dos estados investigados, decidiu-se considerar como de oposição os deputados que se localizaram nas posições de sete (7) a dez (10) na escala.

(b) Na dimensão ideológica, utilizou-se o índice de polarização proposto por Francisco A. Ocaña e Pablo Oñate (apud Díez e Barahona, 2002:348). Tal medida considera a soma das diferenças entre as posições de cada partido na escala direita versus esquerda, em relação à média da posição do conjunto de partidos do plenário, elevada ao quadrado e ponderada pelo peso dos partidos na Assembleia. Esse peso, por sua vez, é indicado pelo número de cadeiras que cada um deles obteve nas urnas em $2006^{19}$. O resultado, para cada uma das Casas Legislativas, foi padronizado de forma a variar de 0 a 1, para que esse indicador contasse, na construção do índice, com o mesmo peso dos outros dois ${ }^{20}$.

(c) Com relação à terceira dimensão, a dispersão política, considerou-se o índice de fragmentação parlamentar proposto por Rae e Taylor (1970). A fragmentação parlamentar resulta da relação entre a fracionalização, medida proposta anteriormente por Rae, e a fraciona- 
lização máxima, que mede a relação entre o número de cadeiras e o número de partidos parlamentares ${ }^{21}$.

O Quadro 2 mostra os resultados obtidos nos indicadores considerados na construção do índice de competição legislativa para os estados analisados. Também nesse caso o valor foi calculado pela soma dos três indicadores, padronizados de forma a terem o mesmo peso. Assim, o índice de competição legislativa pode variar de zero (0), situação em que não haveria nenhuma competição, a três (3), caso de máxima competitividade.

Quadro 2

Índice de Competição Legislativa Estadual (2006)

\begin{tabular}{|l|c|c|c|c|}
\hline Estados & $\begin{array}{c}\text { Oposição (pa- } \\
\text { dronizado) }\end{array}$ & $\begin{array}{c}\text { Polarização } \\
\text { (padronizado) }\end{array}$ & $\begin{array}{c}\text { Fragmentação } \\
\text { (padronizado) }\end{array}$ & ICL \\
\hline Ceará & 0,03 & 0,29 & 0,00 & 0,32 \\
\hline Goiás & 0,61 & 0,00 & 0,26 & 0,87 \\
\hline Mato Grosso & 0,00 & 0,41 & 0,57 & 0,98 \\
\hline Santa Catarina & 0,49 & 0,41 & 0,42 & 1,32 \\
\hline Minas Gerais & 0,22 & 0,43 & 0,87 & 1,52 \\
\hline Pará & 0,73 & 0,23 & 0,61 & 1,57 \\
\hline Rio de Janeiro & 0,56 & 0,35 & 0,67 & 1,58 \\
\hline São Paulo & 0,53 & 0,63 & 0,45 & 1,60 \\
\hline Tocantins & 0,98 & 0,30 & 0,43 & 1,72 \\
\hline Bahia & 0,47 & 1,00 & 0,57 & 2,04 \\
\hline Pernambuco & 0,62 & 0,57 & 0,86 & 2,04 \\
\hline Rio Grande do Sul & 1,00 & 0,68 & 1,00 & 2,68 \\
\hline
\end{tabular}

Fonte: TSE (2009); survey Elites Políticas - CEL-DCP (2008).

Também no grau de competição legislativa, há diferença entre os casos analisados. A leitura do Quadro 2 permite observar que Ceará, Goiás e Mato Grosso apresentam menor competição legislativa, em contraste com Bahia, Pernambuco e Rio Grande do Sul, com maior competição legislativa.

Os dois índices distribuem os estados de forma diferente. Esse resultado indica que eles devem ser tratados como dimensões separadas. Embora os dois índices estejam correlacionados $\left(\mathrm{R}^{2}=0,67\right)$, parece relevante distinguir, para analisar os subsistemas estaduais, a competição 
na arena eleitoral, de um lado, e a competição na arena legislativa, de outro.

\section{A Classificação dos Subsistemas Partidários Estaduais}

Seguindo os passos de Lima Júnior (1983), interessa fazer a classificação dos sistemas políticos estaduais em termos dos graus de competição política. No Gráfico 1, os estados analisados foram colocados em dois eixos: o primeiro apresenta os resultados no índice de competição eleitoral, o segundo mostra os valores do índice de competição legislativa. Pode-se observar que a maioria dos casos se encontra nos dois quadrantes inferiores, de baixa competição eleitoral; não há casos na posição de alta competição eleitoral e baixa competição legislativa, embora o estado do Pará se aproxime dessa posição; Minas Gerais, Tocantins, São Paulo e Rio de Janeiro têm baixa competição eleitoral e alta competição legislativa, embora todos esses casos se encontrem próximos dos centros das distribuições; Rio Grande do Sul, Bahia, Pernambuco e Pará são os estados que têm posição alta nos dois índices.

\section{Gráfico 1}

Posições dos Estados nos Índices de Competição Eleitoral e Legislativa (2006)

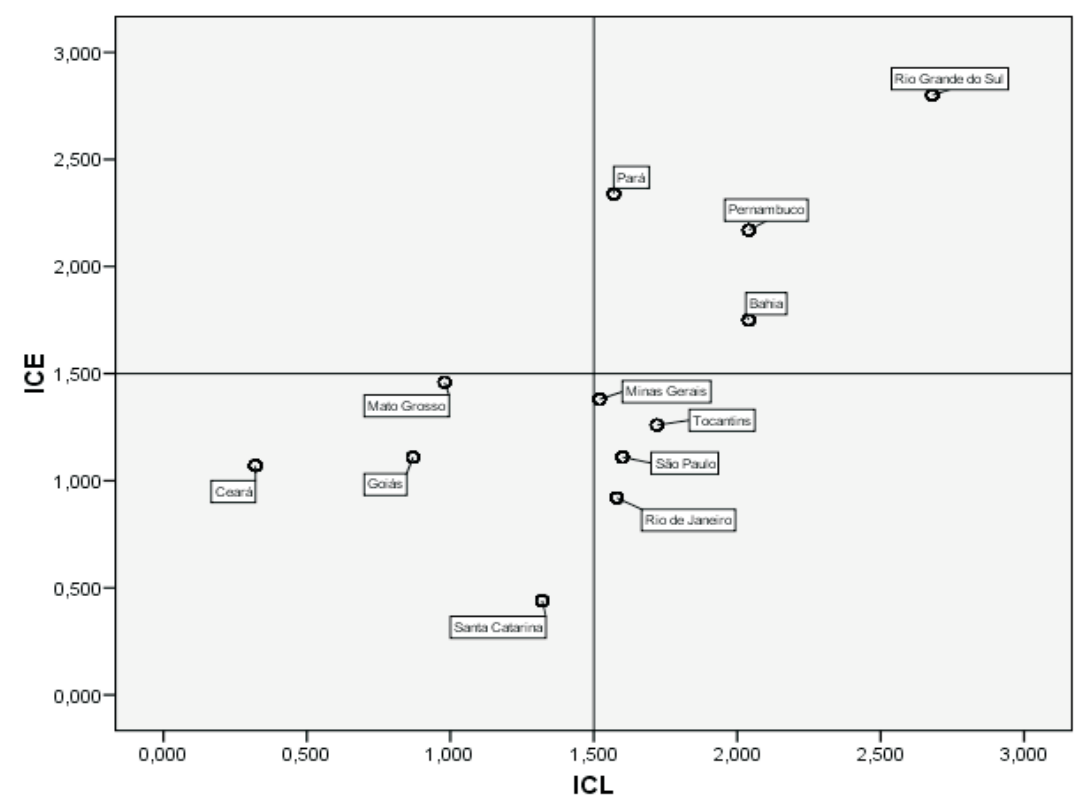

Fonte: Survey Elites Políticas - CEL-DCP (2008). 
Esses resultados confirmam que a heterogeneidade dos subsistemas partidários encontrada por Lima Júnior (1983) para o período de 1945 a 1964 vale também para o atual período. Se os resultados das eleições legislativas de 2006 não têm características específicas, diferentes das dos outros pleitos da atual democracia brasileira, os dados acima mostram a permanência de tipos diferentes de subsistemas estaduais, com referência aos graus de competição política nas unidades federadas. Resta examinar, como proposto na hipótese formulada anteriormente, se esse fator, que distingue os estados investigados, tem algum impacto sobre a variável dependente, particularismo versus universalismo do comportamento dos deputados estaduais entrevistados.

\section{Variáveis Independentes II: Posicionamento Ideológico, Apoiadores Consistentes e Tipo de Base Eleitoral}

Além da possibilidade de que a competição política (eleitoral e legislativa) tenha alguma influência sobre o comportamento particularista dos deputados estaduais analisados, aventam-se as hipóteses, formuladas no início, de que o partido de filiação do deputado, os tipos de apoiadores consistentes e de bases eleitorais tenham também efeito sobre o grau de particularismo do comportamento dos legisladores. A seguir, apresenta-se a forma como essas últimas variáveis foram medidas.

(a) Como indicador da filiação partidária do deputado utilizou-se a medida da posição ideológica dos partidos políticos no eixo esquerda versus direita, como informada acima, quando se explicitou a construção dos índices de competição política. Espera-se que deputados de partidos de direita tenham comportamento mais particularista que deputados de partidos de esquerda ${ }^{22}$. A distribuição dessa variável é apresentada no Gráfico 2.

(b) Para classificar os tipos de apoiadores consistentes, seguindo a orientação de Arnold (1990), foram utilizadas três variáveis indicadoras (dummies), construídas a partir da seguinte pergunta incluída no questionário: "Na opinião do(a) Sr.(a), qual dos seguintes fatores foi o mais importante para sua vitória na última eleição?". A resposta "o apoio do partido" foi classificada como apoio de tipo geral; as respostas "o apoio de prefeitos de sua região" e "o apoio de vereadores de sua região" foram tomadas como indicadores de apoio de tipo regional, e "o apoio de líderes empresariais", "da Igreja" e "de líderes comunitários ou sindicais", tomadas como apoio de tipo grupal. As demais respos- 


\section{Gráfico 2}

Distribuição dos Deputados por Posicionamento Ideológico Médio, no Eixo Esquerda versus Direita, dos Partidos a que São Filiados

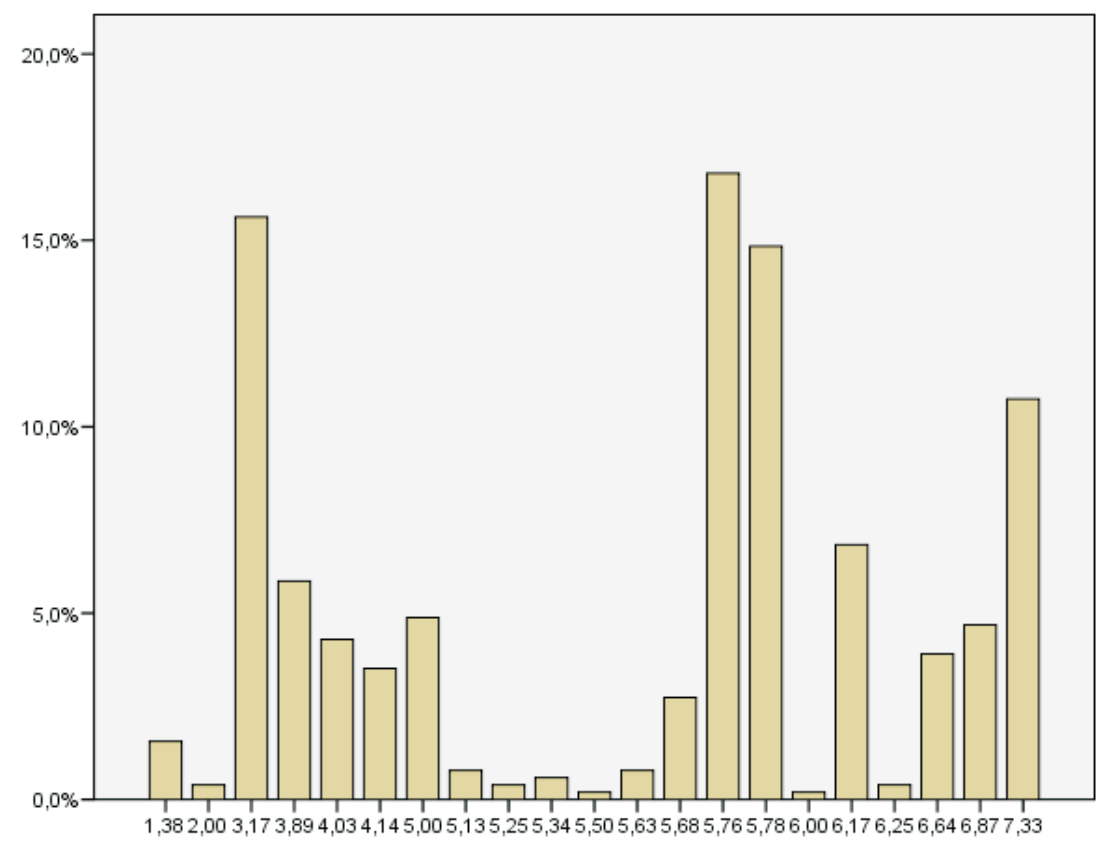

Posicionamento ideológico

Fonte: Survey Elites Políticas - CEL-DCP (2008).

tas foram consideradas "outros apoios". As três variáveis indicadoras, "apoiadores de tipo geral", "apoiadores de tipo regional" e "apoiadores de tipo grupal", foram calculadas em contraposição ao "apoio de outros". Espera-se, a partir do esquema analítico proposto, que respostas indicando o apoio regional como o fator mais importante para a vitória eleitoral dos deputados estejam associadas com comportamento mais particularista. No Gráfico 3 pode-se observar a distribuição dos deputados na variável "apoiadores consistentes".

(c) Para a criação do indicador de "base eleitoral" utilizou-se o que se chamou, no questionário, de "representação prioritária" dos deputados. Três variáveis indicadoras foram construídas a partir da seguinte pergunta: "Nesta legislatura, o(a) Sr.(a) acredita representar prioritariamente os interesses de:". Foram classificados como representantes de interesses gerais os deputados que responderam "dos eleitores de seu partido"; como representantes de base regional os que afirmaram "dos 


\section{Gráfico 3}

Distribuição dos Deputados na Variável Apoiadores Consistentes

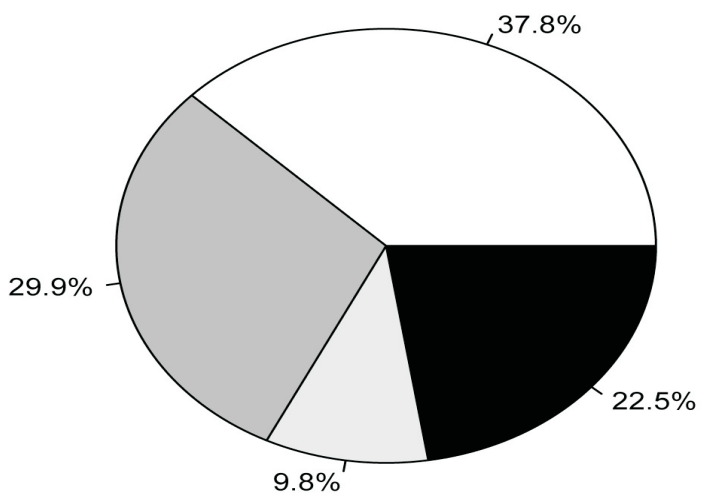

$$
\begin{aligned}
& \square \quad \text { Apoiadores Grupais }(37,8 \%) \\
& \square \text { Apoiadores Regionais }(29,9 \%) \\
& \square \quad \text { Apoiadores Universais }(9,8 \%) \\
& \square \text { Outros }(22,5 \%)
\end{aligned}
$$

Fonte: Survey Elites Políticas - CEL-DCP (2008).

eleitores de sua região"; e como representantes de interesses grupais os que responderam "de determinado segmento (social, religioso, econômico) de cidadãos de seu estado". As variáveis "representantes de interesses gerais", "representantes de bases regionais" e "representantes de interesses grupais" foram calculadas em relação às "outras" bases apontadas pelos parlamentares. Espera-se comportamento mais particularista entre os deputados que afirmam representar prioritariamente os interesses dos eleitores de sua região e, em menor medida, entre os que afirmam representar grupos sociais. A distribuição dos deputados nessa variável é apresentada no Gráfico 4.

\section{Variável Dependente: O Grau de Particularismo dos Deputados}

A variável dependente "o grau de particularismo do comportamento dos deputados tomados individualmente" foi medida por meio de um índice somatório ${ }^{23}$, criado a partir dos seguintes itens incluídos no questionário:

(a) a importância atribuída pelo deputado à função de "propor emendas ao orçamento estadual que beneficiem sua região". Foram atribuídos quatro (4) pontos ao deputado se ele afirmou dar importância "em 
Determinantes do Comportamento Particularista de Legisladores...

\section{Gráfico 4}

Distribuição dos Deputados na Variável Tipo de Base Eleitoral
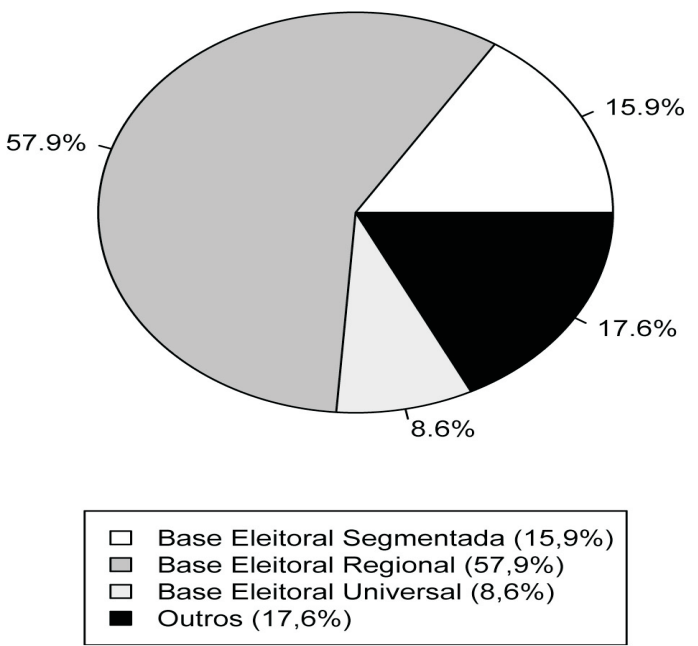

Fonte: Survey Elites Políticas - CEL-DCP (2008).

primeiro lugar" a essa função, dois (2) pontos se afirmou "em segundo lugar" e zero (0) se não citou essa função entre as duas mais importantes;

(b) a frequência com que os deputados afirmam ter realizado, na atual legislatura, a atividade de "atender ou encaminhar pleitos de seus eleitores". A resposta a esse item foi medida, no questionário, utilizando-se a seguinte escala: muitas vezes, algumas vezes, poucas vezes ou nunca; os números, de zero (0) a quatro (4), foram atribuídos aos deputados de acordo com o grau crescente em sua resposta sobre a frequência dessa atividade;

(c) a frequência com que os deputados afirmam ter realizado, na atual legislatura, a atividade de "tratar, junto à burocracia, das demandas de prefeitos de sua região". Esse item foi medido da mesma forma que o anterior;

(d) a importância atribuída pelo respondente a "conseguir recursos para sua base eleitoral", para o candidato se reeleger à Assembleia Legislativa. Os valores de zero (0) a quatro (4), nesse item, foram atribuídos de acordo com a ordenação, feita pelos deputados, de um conjunto de cinco itens alternativos; 
(e) a frequência com que o deputado utiliza "visitas às suas bases eleitorais" como meio para informar seus eleitores sobre sua atuação parlamentar. Os pontos, de zero (0) a quatro (4), foram atribuídos aos deputados de acordo com uma escala de resposta que variava de "nunca" a "frequentemente".

O índice construído tem um resultado estatisticamente consistente ${ }^{24}$. Para o conjunto dos deputados, o grau de particularismo parece alto: a medida variou de 2,67 a 20 pontos, com média de 14,77 e desvio padrão de 3,38. O Gráfico 5 mostra a distribuição do índice de particularismo para todos os entrevistados.

No Gráfico 6, pode-se observar a variação do comportamento particularista entre os estados da Federação investigados. Os casos foram ordenados dos menores aos maiores valores em relação à média. Note-se que não há um padrão regional claro na distribuição do comportamento particularista médio dos parlamentares. Os menores graus médios de comportamento particularista aparecem no Rio de Janeiro (Sudeste) ${ }^{25}$, no Rio Grande do Sul (Sul), mas também em Pernambuco (Nor-

\section{Gráfico 5}

Distribuição do Índice de Particularismo (todos os deputados entrevistados)

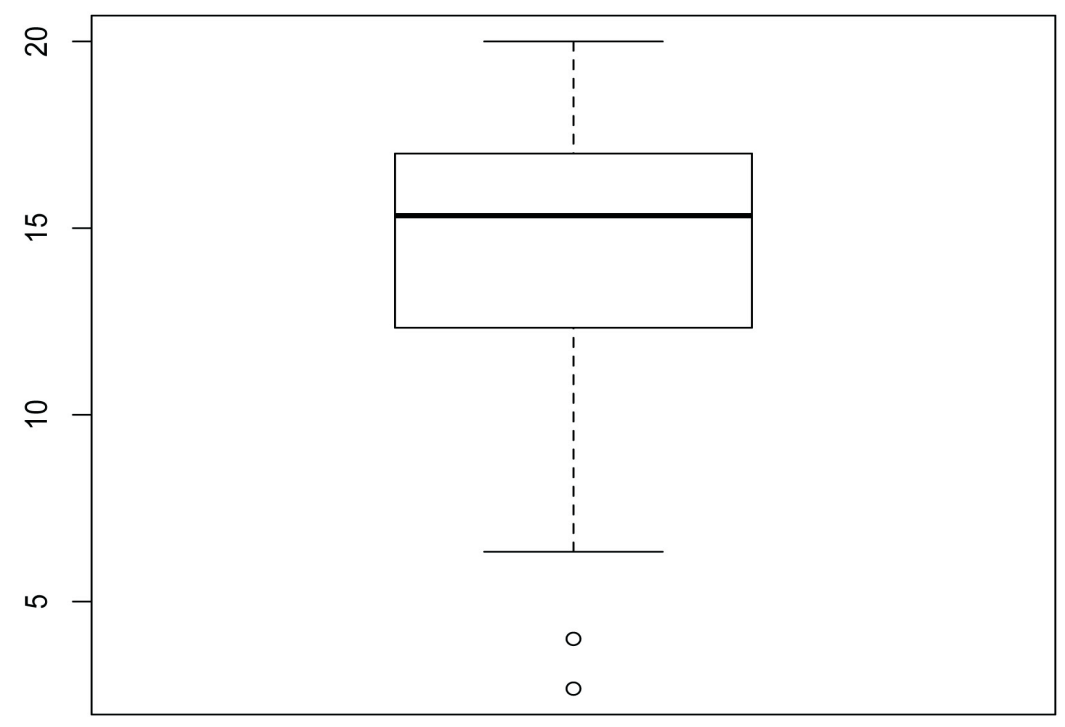

Fonte: Survey Elites Políticas - CEL-DCP (2008). 


\section{Gráfico 6}

Comportamento Particularista por Estados da Federação Incluídos na Pesquisa (média e intervalo de confiança)

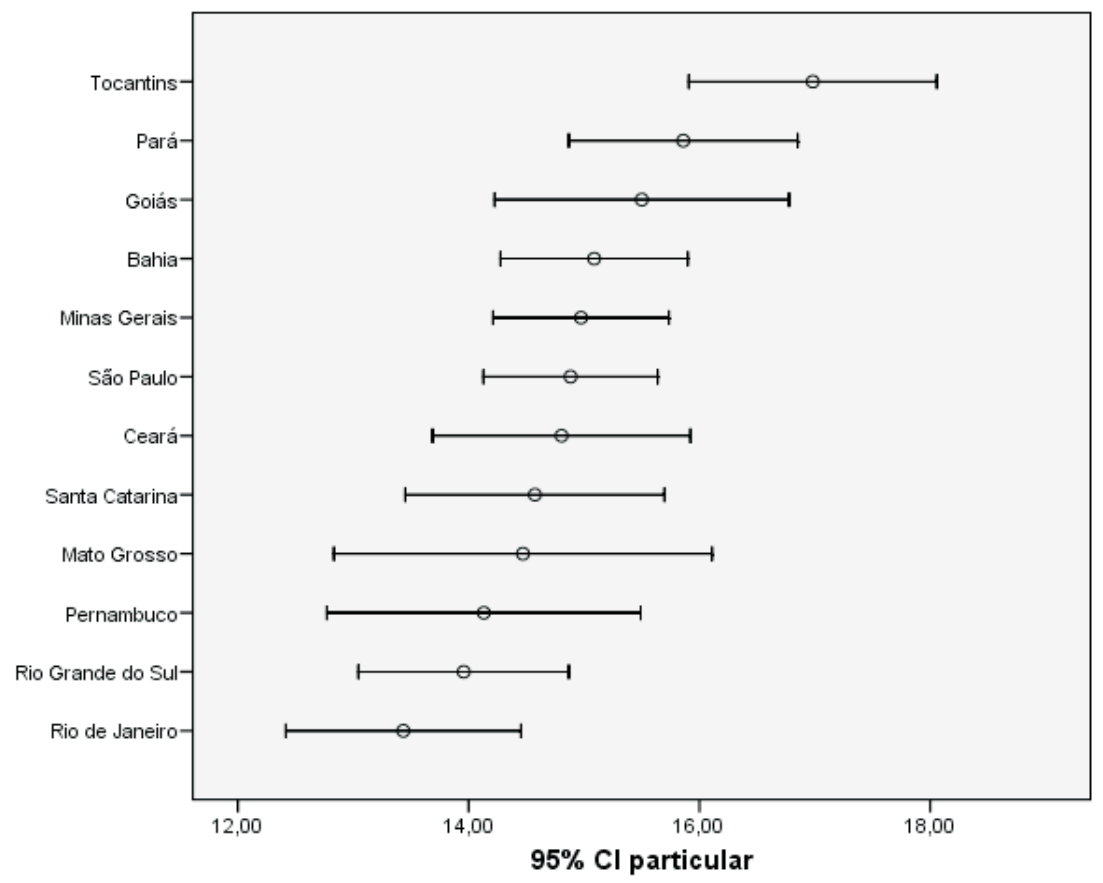

Fonte: Survey Elites Políticas - CEL-DCP (2008).

deste); a maior presença média de particularismo foi encontrada no Tocantins (Norte), no Pará (Norte) e em Goiás (Centro-Oeste).

A Tabela 1 apresenta os partidos ordenados de acordo com o grau de particularismo médio de seus deputados. $\mathrm{O}$ índice ordena os entrevistados, classificados por partidos políticos, de forma compatível com a que se poderia esperar: note-se que essa classificação corresponde de perto à distribuição dos partidos na escala direita versus esquerda apresentada anteriormente. De acordo com a literatura especializada em partidos políticos (Melo, 2000; 2004), aqueles mais à direita apresentam média de grau de particularismo maior do que a observada nos posicionados mais à esquerda.

\section{O Teste das Hipóteses}

As tabelas 3 e 4 trazem os resultados dos testes das hipóteses, feitos por meio de quatro modelos de regressão linear múltipla ${ }^{26}$, a fim de anali- 
Tabela 1

Variação do Índice de Comportamento Particularista por Partido (número, valor mínimo, máximo, média e desvio padrão)

\begin{tabular}{|c|c|c|c|c|c|}
\hline Partido & $\mathbf{N}$ & Mín. & Máx. & Média & Desvio Padrão \\
\hline PSOL & 2 & 8,3 & 11 & 9,67 & 1,89 \\
\hline PTN & 1 & 11 & 11 & 11 & - \\
\hline PRB & 3 & 11,3 & 14 & 12,89 & 1,39 \\
\hline $\mathrm{PT}$ & 80 & 6,3 & 20 & 12,90 & 2,99 \\
\hline PC do B & 8 & 8,7 & 16 & 13,79 & 2,36 \\
\hline PHS & 4 & 10 & 17,3 & 13,83 & 3,42 \\
\hline PDT & 30 & 8,0 & 20 & 13,97 & 3,31 \\
\hline PPS & 18 & 4,0 & 20 & 13,98 & 4,26 \\
\hline PV & 16 & 4,0 & 20 & 14,04 & 3,97 \\
\hline PMN & 4 & 11,3 & 20 & 14,83 & 3,71 \\
\hline PAN & 3 & 12 & 18 & 14,89 & 3,01 \\
\hline PSB & 22 & 7,7 & 20 & 14,92 & 3,33 \\
\hline PSDC & 2 & 11 & 19 & 15 & 5,66 \\
\hline PMDB & 76 & 6,7 & 20 & 15,02 & 3,51 \\
\hline PSC & 14 & 2,7 & 20 & 15,26 & 4,64 \\
\hline PSDB & 86 & 7,3 & 20 & 15,36 & 3,25 \\
\hline DEM & 55 & 8,3 & 20 & 15,38 & 3,01 \\
\hline PP & 24 & 6,7 & 20 & 15,50 & 2,97 \\
\hline PTC & 2 & 15,3 & 16 & 15,67 & 0,47 \\
\hline PR & 20 & 10,7 & 20 & 15,87 & 2,31 \\
\hline РТВ & 32 & 10,7 & 20 & 16,28 & 2,78 \\
\hline PT do B & 4 & 13,3 & 20 & 17 & 2,80 \\
\hline PSL & 5 & 16 & 20 & 17,73 & 1,74 \\
\hline PRP & 1 & 18 & 18 & 18 & - \\
\hline
\end{tabular}

Fonte: Survey Elites Políticas - CEL-DCP (2008).

sar o impacto dos diversos fatores tratados como variáveis independentes sobre o grau de comportamento particularista dos deputados nas doze Casas Legislativas pesquisadas.

No primeiro modelo foram incluídos os índices de competição eleitoral (ICE) e legislativa (ICL). O coeficiente do ICE é positivo e o do ICL, negativo, o que mostra a importância de se levar em conta as duas medidas separadamente. Com o controle do ICL, o efeito da competição eleitoral tem sinal positivo: o grau de particularismo do comporta- 
mento dos deputados aumenta com mais competição eleitoral, ao contrário do que se esperava. Contudo, a competição legislativa, controlada a competição eleitoral, implica diminuição, como se propôs na hipótese, do grau de particularismo do comportamento legislativo. Esse é um dos achados interessantes deste trabalho. Embora teoricamente se esperasse que o efeito das duas dimensões de competição política se desse na mesma direção, empiricamente foram observados efeitos em sentidos opostos ${ }^{27}$. Como o erro de estimação encontrado não permite afirmar algo, com segurança, a respeito da magnitude da associação entre competição eleitoral e parlamentar e o comportamento particularista dos deputados, só é possível dizer que a competição política estadual não provocou o efeito esperado.

Os resultados obtidos, portanto, alimentam a discussão sobre a direção da associação entre distributivismo e competição política e indicam que o incremento da competição eleitoral contribui para a elevação do grau de particularismo dos deputados, reforçando o argumento de Lindbeck e Weibull (1993). Segundo esses autores, recursos particularistas são enviados em maior grau para lugares onde há predominância de "swing voters". Isso implica que, ali onde a competição política é maior (os eleitores são mais disputados, não há predomínio de nenhum partido ou facção, os resultados são incertos), são também maiores as chances de conquistar eleitores que votavam em outros candidatos. Esses seriam, portanto, os locais que tendem a receber maior atenção dos incumbents.

Conforme mencionado acima, os resultados mostraram ainda que, quanto maior a competição legislativa estadual, menor tende a ser o grau de particularismo dos deputados. A contribuição deste artigo para a polêmica, portanto, diz respeito às particularidades das duas arenas aqui analisadas: a eleitoral e a legislativa. A literatura que aborda o tema do distributivismo tem considerado a dimensão da competição política unitária; e talvez por isso venha encontrando resultados discrepantes. Na verdade, o que este trabalho sugere é que a competição política impacta o grau de particularismo de incumbents, dependendo da arena política em que ela é medida.

No Modelo 2, foi incluída a variável "partido do deputado", medida por posicionamento na escala esquerda versus direita. O resultado mostra que o posicionamento ideológico do partido do parlamentar afeta seu comportamento: quanto mais à direita se localiza o partido, 
Tabela 3

Modelo de Regressão Linear Múltipla (MQO)

Variável Dependente: Índice de Particularismo (varia de 0 a 20)

\begin{tabular}{|c|c|c|c|}
\hline & $\begin{array}{c}\text { Modelo 1: } \\
\text { Competição } \\
\text { Política } \\
\text { Estadual }\end{array}$ & \begin{tabular}{|c} 
Modelo 2: \\
Posicionamento \\
Ideológico dos \\
Partidos do \\
Representante \\
\end{tabular} & $\begin{array}{l}\text { Modelo 3: } \\
\text { Apoiadores } \\
\text { Consistentes }\end{array}$ \\
\hline & B & B & B \\
\hline Constante & $\begin{array}{l}15,18^{*} \\
(0,45)\end{array}$ & $\begin{array}{l}11,49 * \\
(0,56)\end{array}$ & $\begin{array}{l}11,84^{*} \\
(0,64)\end{array}$ \\
\hline ICE & $\begin{array}{r}0,33 \\
(0,31) \\
\end{array}$ & & \\
\hline ICL & $\begin{array}{l}-0,57 \\
(0,35) \\
\end{array}$ & & \\
\hline $\begin{array}{l}\text { Posicionamento ideológico do } \\
\text { partido do deputado }\end{array}$ & & $\begin{array}{l}0,62^{*} \\
(0,10) \\
\end{array}$ & $\begin{array}{l}0,47^{*} \\
(0,10) \\
\end{array}$ \\
\hline $\begin{array}{l}\text { Apoiadores consistentes de tipo } \\
\text { geral }\end{array}$ & & & $\begin{array}{r}0,01 \\
(0,54) \\
\end{array}$ \\
\hline $\begin{array}{l}\text { Apoiadores consistentes de tipo } \\
\text { regional }\end{array}$ & & & $\begin{array}{l}1,63^{*} \\
(0,39) \\
\end{array}$ \\
\hline $\begin{array}{l}\text { Apoiadores consistentes de tipo } \\
\text { grupal }\end{array}$ & & & $\begin{array}{l}-0,33 \\
(0,38) \\
\end{array}$ \\
\hline $\mathrm{N}$ & 512 & 511 & 509 \\
\hline
\end{tabular}

Fonte: Survey Elites Políticas - CEL-DCP (2008).

Nota: ${ }^{*}$ Sig $<0,05$.

maior a probabilidade de que o deputado se comporte de forma particularista (um ponto a mais na escala eleva 0,62 ponto na escala de particularismo). Esse dado certamente sugere a relevância de se levar em conta essa variável na explicação da atividade parlamentar.

Se for possível considerar, com esse resultado, que o partido do candidato influi sobre seu comportamento mais ou menos particularista, duas interpretações relacionadas parecem plausíveis: 1) os políticos com experiências, origens e bases políticas que incentivam o particularismo tendem a se filiar mais provavelmente aos partidos de direita; ou 2) pode ser que partidos de posição ideológica à esquerda impeçam, com frequência maior, o ingresso, em seus quadros, de políticos de tradição regional, em contraste com representantes de interesses de gru- 
pos específicos e com políticos de orientação programática e ideológica.

Já o Modelo 3 inclui os chamados "apoiadores consistentes" dos deputados. Nesse caso, ter apoiadores consistentes tipicamente regionais (prefeitos, vereadores) faz aumentar, como se esperava teoricamente, a chance de comportamento particularista dos deputados (ter apoiadores consistentes de tipo regional eleva em 1,63 ponto a posição na escala de particularismo). Levando-se em conta o tamanho do erro padrão estimado, frente aos estimadores calculados, ter apoio de grupos específicos (líderes sindicais, comunitários e religiosos, empresários etc.) tem efeito pequeno sobre o comportamento particularista dos deputados, assim como ter apoio geral, de tipo partidário.

O próximo passo foi testar o Modelo 4, no qual foram consideradas as variáveis indicadoras da representação prioritária, mantidas as que se referem ao posicionamento ideológico dos partidos dos deputados e aos apoiadores consistentes de tipo regional, e reintroduzidas as variáveis de competição política. Os resultados mostram que, se o deputado afirma representar prioritariamente os interesses de sua região, aumentam as chances de seu comportamento particularista, controlando-se as demais variáveis. No entanto, se o parlamentar afirma representar algum grupo social, diminuem tais chances. O valor do beta estimado para "representante de interesses gerais" é baixo e não significativo, enquanto o coeficiente para "representantes de bases regionais", ao contrário, é alto e significativo ${ }^{28}$. Importa também observar que o posicionamento ideológico dos partidos dos deputados e os "apoiadores consistentes de base regional" continuam tendo efeito importante sobre o grau de comportamento particularista dos entrevistados.

Os resultados da regressão apontam para a consistência da conexão entre o tipo de representação prioritária, o tipo de apoiadores consistentes, o posicionamento ideológico do partido ao qual o parlamentar é filiado e seu grau de comportamento particularista.

Se os parlamentares são atores racionais que pretendem maximizar suas chances eleitorais por meio do comportamento legislativo, faz sentido encontrar uma relação positiva entre base eleitoral de tipo regional, marcada por concentração espacial de demandas, e comportamento particularista, caracterizado pela busca de benefícios localizados e paroquiais. Assim também é razoável que a relação entre apoiadores consistentes regionais e particularismo seja positiva. Afinal, o 


\section{Tabela 4}

Modelo de Regressão Linear Múltipla (MQO)

Variável Dependente: Índice de Particularismo (varia de 0 a 20)

\begin{tabular}{l|c}
\hline & $\begin{array}{c}\text { Modelo 4: } \\
\text { Tipo de Base Eleitoral } \\
\text { B }\end{array}$ \\
\hline Constante & $11,49^{*}$ \\
& $(0,75)$ \\
\hline ICE & 0,35 \\
& $(0,29)$ \\
\hline ICL & $-0,49$ \\
& $(0,32)$ \\
\hline Posicionamento ideológico do partido do deputado & $0,38^{*}$ \\
& $(0,10)$ \\
\hline Representantes de interesses gerais & $1,46^{*}$ \\
& $(0,31)$ \\
\hline Representantes de bases regionais & 0,56 \\
\hline Representantes de interesses grupais & $(0,57)$ \\
\hline
\end{tabular}

Fonte: Survey Elites Políticas - CEL-DCP (2008).

Nota: ${ }^{*}$ Sig $<0,05$.

atendimento às demandas particulares dos que apoiam o deputado manterá o vínculo que, na opinião dos parlamentares, foi decisivo para sua vitória eleitoral.

\section{CONSIDERAÇÕES FINAIS}

Alguns resultados do esforço de pesquisa sobre os Legislativos estaduais aqui relatados parecem relevantes.

Em primeiro lugar, foi possível, utilizando-se variáveis obtidas por diferentes técnicas de pesquisa, classificar os estados da Federação estudados levando-se em conta duas dimensões consideradas na produção internacional: os graus de competição na arena eleitoral e na arena legislativa. Reforça-se a conclusão de Lima Júnior (1983) para o período 1945-1964: existem diversos subsistemas político-partidários nas uni- 
dades federadas brasileiras; há estados com altos graus de competição eleitoral e legislativa; há casos com baixos graus nos dois índices; e há ainda outros com alto grau de competição eleitoral e baixo grau de competição legislativa. Apesar de as mesmas regras eleitorais valerem para todos eles, os padrões de competição eleitoral e legislativa variam, o que sugere o desenvolvimento de hipóteses explicativas para tal fenômeno. Note-se, no entanto, que a tipologia proposta por Lima Júnior para a democracia de 1945-1964 - sistemas de dois partidos, de três a cinco partidos e de seis ou mais partidos - não é mais adequada para distinguir os tipos de subsistemas partidários estaduais atuais, uma vez que todos os doze casos examinados, em 2006, seriam classificados na terceira categoria (o menor número efetivo de partidos para os estados aqui analisados é de 5,7, caso do Estado do Ceará).

Em segundo lugar, foi possível classificar a grande maioria dos partidos políticos brasileiros na escala direita versus esquerda, também de forma coerente com o conhecimento acumulado e, importa lembrar, a partir da opinião de atores politicamente relevantes: as elites políticas estaduais (deputados das Assembleias Legislativas das unidades pesquisadas). A medida proposta pode, certamente, ser útil em outros estudos sobre o funcionamento do sistema político brasileiro.

Identificou-se, em terceiro lugar, uma dimensão relevante para distinguir o comportamento dos deputados: o grau de particularismo em contraposição ao universalismo de sua atuação política, questão tradicionalmente considerada na produção teórica sobre estudos legislativos.

Certamente, esses resultados já compensariam o esforço de pesquisa realizado pela equipe do CEL-DCP. Entretanto, o objetivo de verificar os efeitos dos fatores acima sobre o grau de comportamento particularista, como atributo dos deputados, baseado nos pressupostos analíticos e nas teorias em voga na ciência política contemporânea, não foi tão bem-sucedido. Os resultados mostraram, em geral, baixa capacidade preditiva de alguns dos fatores considerados na análise. Não foi possível sustentar, com evidências suficientes, que os graus de competição política estadual têm efeito relevante sobre as tendências de comportamento particularista dos representantes eleitos.

Como apontado neste artigo, a variação do grau de particularismo entre deputados de uma mesma Casa Legislativa relaciona-se: 1) ao posicionamento ideológico dos partidos a que são filiados; e 2) à dimensão 
explorada pelos estudos sobre conexão eleitoral. Vale assinalar a maior probabilidade de comportamento particularista dos deputados filiados a partidos mais à direita e a associação encontrada entre o tipo de apoiadores consistentes e de base eleitoral dos deputados e o grau de particularismo de seu comportamento legislativo. A prudência recomenda, no entanto, a necessidade de se examinar essas conclusões à luz de dados sobre a distribuição geográfica da votação obtida pelos parlamentares, assim como de informações sobre o modelo de organização legislativa e o grau de desenvolvimento institucional apresentados por Casas Legislativas de diferentes estados.

Os resultados apontam, ademais, para a relevância de se aprofundar a investigação do objeto aqui proposto por meio de estudos comparativos longitudinais que incluam informação sobre os outros estados da Federação. É preciso considerar também outras dimensões que possam definir e distinguir as condições em que se dá a atuação política dos deputados estaduais: pode ser importante levar em conta, além de outros fatores da dimensão político-institucional, a diversidade econômica e social existente entre os estados da Federação.

(Recebido para publicação em março de 2009)

(Versão definitiva em dezembro de 2009)

\section{NOTAS}

1. "All members of Congress have a primary interest in getting re-elected. Some members have no other interest" (Frank E. Smith apud Mayhew, 1974:16).

2. O projeto foi financiado pela Fundação de Amparo à Pesquisa do Estado de Minas Gerais (Fapemig), pelo Conselho Nacional de Desenvolvimento Científico e Tecnológico (CNPq) e pela Coordenação de Aperfeiçoamento de Pessoal de Nível Superior (Capes). Agradecemos a essas instituições.

3. Os autores agradecem aos outros membros da equipe coordenadora da pesquisa, Carlos Ranulfo F. de Melo e Magna Inácio, a possibilidade de utilização dos resultados para a elaboração deste artigo. Agradecem também a colaboração de todas as Casas Legislativas e dos deputados na aplicação do questionário. São gratos, especialmente, à equipe de alunos do Programa de Pós-Graduação do Departamento de Ciência Política e do Curso de Graduação em Ciências Sociais, que trabalhou voluntariamente e com especial envolvimento em todas as etapas de realização da pesquisa. 


\section{Determinantes do Comportamento Particularista de Legisladores...}

4. Encontram-se no Apêndice, Tabela A1, o número e a porcentagem de deputados entrevistados em cada um dos estados pesquisados.

5. "Another kind of difference appears if the initial assumption of a reelection quest is relaxed to take into account the 'progressive' ambitions of some members - the aspirations of some to move up to higher electoral offices rather than keep the ones they have" (Mayhew, 1974:75).

6. Além das diferenças nas trajetórias de carreiras dos parlamentares e nas estratégias empreendidas por eles para a manutenção de seus mandatos, os sistemas eleitorais de Brasil e Estados Unidos têm diferenças marcantes. Como se sabe, no Brasil a representação é proporcional de lista aberta, com distritos de alta magnitude que incentivam a manutenção do multipartidarismo e a relação personalista entre eleitores e representantes. Embora esse último resultado seja semelhante em ambos os casos, o sistema eleitoral norte-americano é majoritário, com distritos uninominais e apenas dois partidos com cadeiras no Legislativo. A combinação dessas regras pode implicar explicações alternativas para o padrão de comportamento dos parlamentares nos dois países.

7. Há extensa literatura sobre os modelos de organização legislativa. Ver, entre outros, Shepsle e Weingast (1994); Krehbiel (1990); e Cox e McCubbins (1993).

8. "The theory does not always predict a unique outcome. My aim is to show how electoral calculations shape everything from legislator's roll-call decisions to the strategies and tactics of coalition leaders" (Arnold, 1990:5-6).

9. "[...] anyone who has a resource that might be used in the election in question. At the ballot box the only usable resources are votes, but there are resources that can be translated into votes: money, the ability to make persuasive endorsements, organizational skills, and so one" (Mayhew, 1974:39).

10. Pretendia-se, originalmente, examinar, também como variável independente, o grau de desenvolvimento institucional das Casas Legislativas considerando duas dimensões principais: os recursos disponíveis para a atuação eficiente dos deputados e a existência e a operação efetiva de mecanismos de interlocução continuada entre legisladores e cidadãos. Em versões anteriores deste estudo, procurou-se medir esses indicadores por meio das opiniões e avaliações dos deputados entrevistados sobre o funcionamento da Casa Legislativa. No entanto, verificou-se que tais informações são passíveis de diferentes interpretações, motivo pelo qual foram retiradas da análise aqui apresentada. O exame dos Regimentos Internos das Assembleias mostrou alguma variação, no plano das normas, nos indicadores dos recursos e procedimentos existentes para a atuação dos deputados, mas não há informações disponíveis sobre a efetividade desses mecanismos. Ademais, não foi possível obter informações sistematizadas, para todos os casos, sobre a existência e a operação efetiva de mecanismos de interlocução continuada entre legisladores e cidadãos. Por esses motivos a variável "desenvolvimento institucional" não foi incluída no teste empírico, apesar do reconhecimento de sua provável importância para explicar o comportamento dos legisladores.

11. Há controvérsias, na literatura, sobre a natureza e a direção da associação entre grau de competição política e grau de particularismo de atores políticos em democracias. O debate entre Lindbeck e Weibull (1993), Dixit e Londregan (1996; 1998), de um lado, e Cox e McCubbins (1986), de outro, constitui uma boa ilustração dessa polêmi- 


\section{Mônica Mata Machado de Castro, Fátima Anastasia e Felipe Nunes}

ca e está apresentado em Dahlberg e Johansson (2002). No presente artigo, optou-se por submeter a teste empírico, para os estados brasileiros estudados, hipótese sustentada nos argumentos de Cox e McCubbins (1986) e de Cox (2008), de que os incumbents investem especialmente naquelas regiões em que têm maior proporção de apoiadores consistentes.

12. Para analisar comparativamente o "desperdício eleitoral", Wanderley Guilherme dos Santos (2008) propôs um índice de competitividade partidária e eleitoral levando em conta o número de candidatos, a magnitude dos distritos e o número de partidos que concorrem às eleições. Neste artigo, decidiu-se propor dois índices, um de competição eleitoral e outro de competição legislativa, levando em conta outros indicadores, além dos propostos por aquele autor. Incluiu-se, especialmente, a distribuição dos votos dos eleitores entre os partidos políticos classificados nas dimensões de direita versus esquerda e oposição versus situação.

13. Os dados foram obtidos no sítio do Tribunal Superior Eleitoral (TSE), consultado em 10 de março de 2009. No Apêndice, pode-se examinar a Tabela A2, que contém as informações e os passos seguidos para o cálculo desse indicador; nela, encontram-se dados sobre o governador eleito, os partidos que participaram da coligação vitoriosa para o governo de cada estado, o número de votos válidos para as Assembleias Legislativas e o número de votos nos partidos que não participaram daquela coligação, na eleição de 2006, nos doze estados pesquisados.

14. No Apêndice, pode-se examinar a Tabela A4, com as médias e os desvios correspondentes, assim como as médias gerais e a ordenação dos partidos políticos que têm representantes nas Assembleias Legislativas, na escala de direita versus esquerda. Somente um dos partidos com representação nas Assembleias Legislativas pesquisadas, o PRTB, não pôde ser classificado porque seus deputados (três) não foram encontrados ou se recusaram a responder o questionário.

15. No Apêndice, é possível examinar a Tabela A3, com todas as informações sobre os passos seguidos para a construção do índice de distância ideológica.

16. Índice de fragmentação eleitoral:

$F=\frac{1-\left(\sum p v^{2}\right)}{N(n-1) / n(N-1)}$. Subtrai-se 1 do somatório da proporção de votos que cada partido obteve na eleição, elevado ao quadrado x 100. O resultado é dividido pela razão entre partidos (n) e votos $(\mathrm{N})$.

17. Na Tabela A5, no Apêndice, podem ser observados os passos seguidos para o cálculo da fragmentação eleitoral para cada um dos estados analisados.

18. Agradecemos ao professor José Francisco Soares por nos ter sugerido adotar o procedimento da padronização dos três indicadores para a construção dos índices de competição eleitoral e de competição legislativa. A simples soma, sem essa padronização, dava menor peso especialmente ao indicador de distância ideológica.

19. A medida é: $P I=\sum C_{i}\left(P_{i}-\bar{P}_{P L}\right)^{2}$, em que $P I=$ polarização ideológica; $C i=$ proporção de cadeiras controladas pelo partido $i$ na posse (2007); $P i$ = posicionamento ideológico do partido $i$; e Ppl = média do posicionamento ideológico do plenário. Ver Francisco A. Ocaña e Pablo Oñate (apud Díez e Barahona, 2002:348).

20. A Tabela A6, no Apêndice, traz os dados referentes à construção dessa medida. Em versões anteriores deste artigo, calculou-se esse indicador somando-se as propor- 


\section{Determinantes do Comportamento Particularista de Legisladores...}

ções de cadeiras de direita e de esquerda e dividindo-se esse resultado pelo total de deputados da Casa. Tal medida foi criticada por alunos e professores em seminário da disciplina Legislativos Subnacionais em Perspectiva Comparada, da pós-graduação em Ciência Política da UFMG, pelo fato de que valores iguais poderiam ocorrer para casos inteiramente diferentes. Outra tentativa de medir a polarização foi considerar a razão entre a proporção da maior bancada, de direita ou de esquerda, e a proporção da menor bancada, também classificada como de direita ou de esquerda, depois padronizada para variar de 0 a 1 . Finalmente, encontrou-se a medida de polarização proposta em Ocaña e Oñate, utilizada por Díez e Barahona (2002).

21. A Tabela A7, no Apêndice, traz esses dados para cada um dos estados analisados. Em versão anterior deste artigo, utilizou-se como indicador de dispersão o número efetivo de partidos políticos em cada estado, dividido por 100 e padronizado em relação ao valor máximo encontrado nas Assembleias Legislativas em 2006. Decidiu-se utilizar a fragmentação parlamentar para que o indicador de dispersão fosse semelhante nos dois índices, de competição eleitoral e parlamentar, e porque a padronização criou problemas para a comparabilidade dos casos. Na versão original do artigo, apresentada no $32^{\circ}$ Encontro da Anpocs, incluiu-se no índice de competição legislativa o resultado de uma questão do questionário em que se perguntava aos deputados se as interações entre governo e oposições "têm sido predominantemente competitivas ou predominantemente cooperativas". Decidiu-se excluir esse indicador e considerar somente medidas que dissessem respeito às características agregadas das Casas Legislativas, seguindo sugestão de Fabiano Santos, que analisou o artigo no Encontro.

22. Ver, a respeito, Nunes (2008).

23. Para medir o comportamento particularista versus universalista, em versão anterior deste artigo, utilizou-se um índice padronizado resultante de análise fatorial dos itens especificados anteriormente. A mudança para um índice somatório foi feita para facilitar a análise e a compreensão dessa variável. Agradecemos ao professor José Francisco Soares por ter observado que todos os indicadores de comportamento particularista deveriam ter o mesmo peso no índice, se não há razão teórica para justificar que um deles pese mais.

24. O alpha de Cronbach foi igual a 0,6. Segundo o Academic Technology Services, Statistical Consulting Group da UCLA, disponível em http://www.ats.ucla.edu/ stat/sas /notes2/ e acessado em 24/11/2007, "o Alpha de Cronbach representa quão bem um conjunto de variáveis mensura um construto latente unidimensional simples. Quando os dados apresentam uma estrutura multidimensional, o alpha de Cronbach é geralmente baixo" (tradução dos autores).

25. Pode causar estranheza o baixo grau de particularismo apresentado pelos deputados do Estado do Rio de Janeiro, em virtude do comportamento conhecido de outras variáveis, como a alta fragmentação do sistema partidário estadual. Talvez esse resultado se deva à configuração demográfica da população desse estado, que se concentra na cidade do Rio de Janeiro, em contraste, por exemplo, com Minas Gerais, estado em que há maior dispersão populacional entre seus 853 municípios.

26. Não foi considerado o $\mathrm{R}^{2}$ ajustado, dadas as controvérsias sobre sua capacidade preditiva. Sobre o tema, ver King (1986) e Gelman e Hill (2007). 


\section{Mônica Mata Machado de Castro, Fátima Anastasia e Felipe Nunes}

27. Tais resultados sugerem novas agendas de pesquisa, incluindo outras variáveis explicativas, além das consideradas neste artigo. Especial consideração merecem as variáveis endógenas à organização legislativa, que podem distribuir diferentes incentivos - positivos e negativos - ao comportamento particularista, a depender do modelo prevalecente na Casa: distributivo, informacional ou partidário (Shepsle e Weingast, 1995; Krebhiel, 1990; Cox e McCubbins, 1993).

28. Comparando-se os betas padronizados desse último modelo, pode-se afirmar que "representação de bases regionais" e "apoiadores consistentes de tipo regional" são as variáveis, entre aquelas testadas neste artigo, que apresentaram a associação mais forte com o grau de comportamento particularista.

\section{REFERÊNCIAS BIBLIOGRÁFICAS}

ABRANCHES, Sérgio. (1988), "Presidencialismo de Coalizão: O Dilema Institucional Brasileiro". DADOS, vol. 31, no 1, pp. 5-38.

AMES, Barry. (2003), Os Entraves da Democracia no Brasil. Rio de Janeiro, Editora FGV.

ANASTASIA, Fátima e MELO, Carlos Ranulfo F. de. (2002), “Accountability: Representação e Estabilidade Política no Brasil", in F. Abrúcio e R. Loureiro (orgs.), O Estado numa Era de Reformas. Os Anos FHC. Brasília, MP/Seges, pp. 25-74.

e SANTOS, Fabiano. (2004), Governabilidade e Representação Política na América do Sul. Rio de Janeiro/São Paulo, Fundação Konrad Adenauer-Stiftung/Ed. Unesp.

ARNOLD, Douglas. (1990), The Logic of Congressional Action. New Haven, Yale University Press.

AVELAR, Lúcia e CINTRA, Antônio Octávio (orgs.). (2002), Sistema Político Brasileiro. Uma Introdução. Rio de Janeiro/São Paulo, Fundação Konrad Adenauer-Stiftung/Fundação Unesp.

CARVALHO, Nelson Rojas. (2003), E no Início Eram as Bases: Geografia Política do Voto e Comportamento Legislativo no Brasil. Rio de Janeiro, Revan.

CHEIBUB, José Antonio, FIGUEIREDO, Argelina e LIMONGI, Fernando. (2002), Presidential Agenda Power and Decision Making in Presidential Regimes: Governors and Political Parties in Brazilian Congress. Trabalho apresentado na reunião anual da American Political Science Association. Boston, 29 de agosto-1o de setembro.

COX, Gary W. (2008), "Swing Voters, Core Voters and Distributive Politics", in P. Swenson, I. Shapiro e D. Donno (eds.), Divide and Deal. The Politics of Distribution in Democracies. New York, New York University Press, pp. 342-357.

e MCCUBBINS, Mathew D. (1986), "Electoral Politics as a Redistributive Game". Journal of Politics, no 48, pp. 370-89. 


\section{Determinantes do Comportamento Particularista de Legisladores...}

(1993), The Legislative Leviathan. Party Government in the House. Berkeley, University of California Press.

(2005), Setting the Agenda. Responsible Party Government in the U. S. House of Representatives. New York, Cambridge University Press.

DAHLBERG, Matz e JOHANSSON, Eva. (2002), “On the Vote-Purchasing Behavior of Incumbent Governments". American Political Science Review, vol. 96, no 1, pp. 27-40.

DÍEZ, Fátima García e BARAHONA, Elena Martínez. (2002), La Estratégia Política y Parlamentaria de los Partidos de Oposición Latinoamericanos: ¿Capacidad de Influencia o Influencia Efectiva? Revista Instituciones y Desarrollo, no 12-13, pp. 331-373.

DIXIT, Avinash e LONDREGAN, John. (1996), “The Determinants of Success of Special Interests in Redistributive Politics". Journal of Politics, no 58, pp. 1132-1155.

(1998), "Ideology, Tactics and Efficiency in Redistributive Politics". Quarterly Journal of Economics, no 113, pp. 497-529.

FENNO, Richard. (1973), Congressmen in Committees. Montreal, Little, Brown and Company.

FIGUEIREDO, Argelina e LIMONGI, Fernando. (1999), Executivo e Legislativo na Nova Ordem Constitucional. Rio de Janeiro, Editora FGV.

. (2002), "Incentivos Eleitorais, Partidos e Política Orçamentária". DADOS, vol. 45, no 2, pp. 303-344.

GELMAN, Andrew e HILL, Jennifer. (2007), Data Analysis Using Regression and Multilevel/ Hierarquical Models. New York, Cambridge University Press.

KING, Gary. (1986), "How Not to Lie with Statistics: Avoiding Common Mistakes in Quantitative Political Science". American Journal of Political Science, vol. 30, no 3, pp. 666-687. Disponível em http:/ /gking.harvard.edu/files/abs/mist-abs.shtml.

KREHBIEL, Keith. (1990), Information and Legislative Organization. Ann Arbor, University of Michigan Press.

LIMAJÚNIOR, Olavo Brasil de. (1983), Os Partidos Políticos Brasileiros. A Experiência Federal e Regional, 1945-1964. Rio de Janeiro, Graal.

LINDBECK, Assar e WEIBULL, Jorgen. (1993), “A Model of Political Equilibrium in a Representative Democracy". Journal of Public Economics, no 51, pp. 195-209.

LOEWENBERG, Gerhard. (2008), "The Contribution of Comparative Research to Measuring the Policy Preferences of Legislators". Legislative Studies Quarterly, vol. 33, no 4, pp. 3-14.

MAINWARING, Scott. (1993), “Democracia Presidencialista Multipartidária: O Caso do Brasil". Lua Nova, no 28-29.

(2001), Sistemas Partidários em Novas Democracias. O Caso do Brasil. Porto Alegre/Rio de Janeiro, Mercado Aberto/Editora FGV.

MAYHEW, David. (1974), Congress. The Electoral Connection. New Haven, Yale University Press.

MELO, Carlos Ranulfo de. (2000), "Partidos e Migração Partidária na Câmara dos Deputados". DADOS, vol. 43, no 2 . 


\section{Mônica Mata Machado de Castro, Fátima Anastasia e Felipe Nunes}

. (2004), Retirando as Cadeiras do Lugar: Migração Partidária na Câmara dos Deputados (1985/2002). Belo Horizonte, Ed. UFMG.

e ANASTASIA, Fátima. (2005), "A Reforma da Previdência em Dois Tempos". DADOS, vol. 42, no 2, pp. 301-332.

NUNES, Felipe. (2008), Governos de Coalizão e Resultados de Soma Positiva em Minas Gerais e no Rio Grande do Sul, 1999-2006. Dissertação de mestrado em Ciência Política, DCP/UFMG, Belo Horizonte.

NICOLAU, Jairo. (2002), “Como Controlar o Representante? Considerações sobre as Eleições para a Câmara dos Deputados no Brasil”. DADOS, vol. 45, no 2, pp. 219-236.

RAE, Douglas. (1971), The Political Consequences of Electoral Laws (2a ed.). New Haven, Yale University Press.

e TAYLOR, Michael. (1970), The Analysis of Political Cleavages. New Haven, Yale University Press.

SAMUELS, David. (2003), Ambition, Federalism and Legislative Politics in Brazil. New York, Cambridge University Press.

SANI, Giacomo e SARTORI, Giovanni. (1980), "Polarización, Fragmentación y Competición en las Democracias Occidentales". Revista del Departamento de Derecho Político (Uned), no 7, pp. 7-37.

SANTOS, Fabiano (org.). (2001), O Poder Legislativo nos Estados: Diversidade e Convergência. Rio de Janeiro, Editora FGV.

(2003), O Poder Legislativo no Presidencialismo de Coalizão. Belo Horizonte, Ed. UFMG.

SANTOS, Wanderley Guilherme dos. (2008), “Competição e Desperdício Eleitoral: Dois Novos Índices". Análise de Conjuntura OPSA, no 5.

SHEPSLE, Kenneth e WEINGAST, Barry. (1994) "Positive Theories of Congressional Institutions". Legislative Studies Quarterly, vol. 19, no 1, pp. 149-179.

(eds.). (1995), Positive Theories of Congressional Institutions. Michigan, The University of Michigan Press.

SOARES, Glaucio e RENNÓ, Lúcio (orgs.). (2006), Reforma Política. Lições da História Contemporânea. Rio de Janeiro, Editora FGV.

VIANNA, Luiz Werneck. (2002), A Democracia e os Três Poderes no Brasil. Belo Horizonte, Ed. UFMG. 


\section{LISTA DE SIGLAS DOS PARTIDOS POLÍTICOS}

DEM - Democratas

PAN - Partido dos Aposentados da Nação

PC do B - Partido Comunista do Brasil

PCB - Partido Comunista Brasileiro

PDC - Partido Democrata Cristão

PDS - Partido Democrático Social

PDT - Partido Democrático Trabalhista

PFL - Partido da Frente Liberal

PHS - Partido Humanista da Solidariedade

PL - Partido Liberal

PMDB - Partido do Movimento Democrático Brasileiro

PMN - Partido da Mobilização Nacional

PP - Partido Progressista

PPB - Partido Progressista Brasileiro

PPR - Partido Progressista Renovador

PPS - Partido Popular Socialista

PR - Partido da República

PRB - Partido Republicano Brasileiro

PRN - Partido da Reconstrução Nacional

PRP - Partido Republicano Progressista

Prona - Partido de Reedificação da Ordem Nacional

PRTB - Partido Renovador Trabalhista Brasileiro

PSB - Partido Socialista Brasileiro

PSC - Partido Social Cristão

PSD - Partido Social Democrata

PSDB - Partido da Social Democracia Brasileira

PSDC - Partido Social Democrata Cristão

PSL - Partido Social Liberal

PSOL - Partido Socialismo e Liberdade

PST - Partido Social Trabalhista

PSTU - Partido Socialista dos Trabalhadores Unificado

PT - Partido dos Trabalhadores

PT do B - Partido Trabalhista do Brasil

PTB - Partido Trabalhista Brasileiro

PTC - Partido Trabalhista Cristão

PTN - Partido Trabalhista Nacional

PV - Partido Verde 
Mônica Mata Machado de Castro, Fátima Anastasia e Felipe Nunes

\section{APÊNDICE}

Tabela A1

Total de Deputados e Entrevistas Realizadas por Estado da Federação

\begin{tabular}{|c|c|c|c|c|}
\hline Estado & $\begin{array}{l}\text { Número Total } \\
\text { de Deputados }\end{array}$ & $\%$ & $\begin{array}{l}\text { Entrevistas } \\
\text { Realizadas }\end{array}$ & $\%$ \\
\hline Bahia & 63 & 10 & 53 & 10,3 \\
\hline Ceará & 46 & 7,3 & 41 & 8 \\
\hline Goiás & 41 & 6,5 & 32 & 6,2 \\
\hline Mato Grosso & 24 & 3,8 & 17 & 3,3 \\
\hline Minas Gerais & 77 & 12,3 & 63 & 12,3 \\
\hline Pará & 41 & 6,5 & 38 & 7,4 \\
\hline Pernambuco & 49 & 7,8 & 38 & 7,4 \\
\hline Rio de Janeiro & 70 & 11,2 & 53 & 10,3 \\
\hline Rio Grande do Sul & 55 & 8,8 & 46 & 9 \\
\hline Santa Catarina & 40 & 6,4 & 36 & 7 \\
\hline São Paulo & 94 & 15,1 & 77 & 15 \\
\hline Tocantins & 24 & 3,8 & 19 & 3,7 \\
\hline Total & 624 & 100 & 513 & 100 \\
\hline
\end{tabular}

Fonte: Survey Elites Políticas - CEL-DCP (2008). 
Determinantes do Comportamento Particularista de Legisladores...

\begin{tabular}{|c|c|c|c|c|c|c|c|c|c|}
\hline \multicolumn{10}{|c|}{ 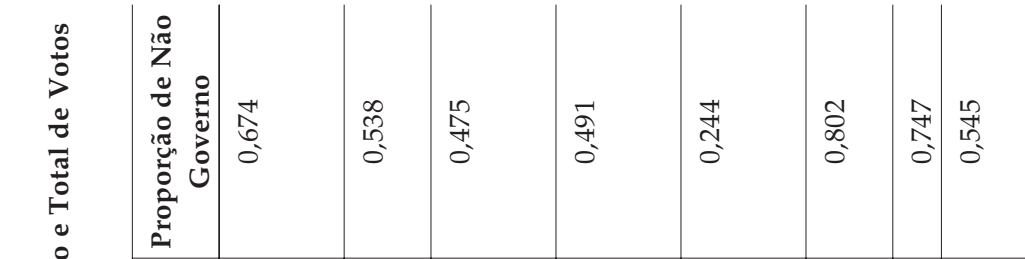 } \\
\hline 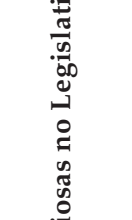 & $\begin{array}{l}n \\
0 \\
: 0 \\
i \pi \\
i \\
0 \\
0 \\
0 \\
0 \\
0\end{array}$ & 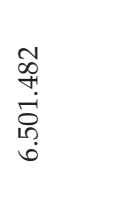 & \begin{tabular}{l}
$\infty$ \\
$\infty$ \\
0 \\
0 \\
0 \\
\hdashline \\
+
\end{tabular} & 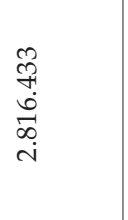 & $\begin{array}{l}\hat{N} \\
\hat{\alpha} \\
\infty \\
\infty \\
\infty \\
\sigma\end{array}$ & 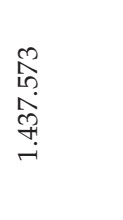 & 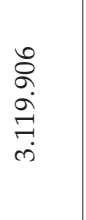 & 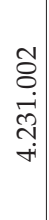 & $\begin{array}{l}30 \\
0 \\
10 \\
\stackrel{1}{1} \\
\infty\end{array}$ \\
\hline 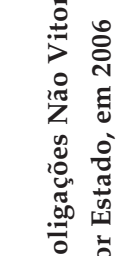 & 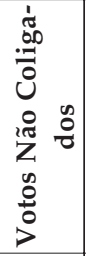 & $\begin{array}{l}\overrightarrow{5} \\
\infty \\
\infty \\
\infty \\
+ \\
+\end{array}$ & $\begin{array}{l}\stackrel{D}{N} \\
\text { D } \\
o \\
\stackrel{N}{N}\end{array}$ & 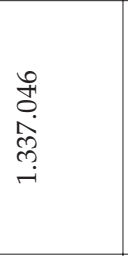 & 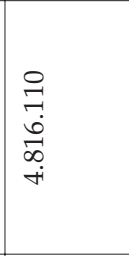 & 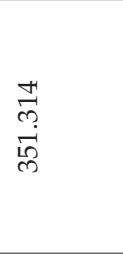 & 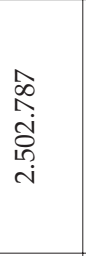 & 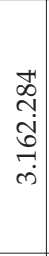 & 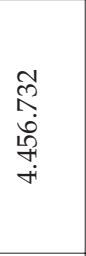 \\
\hline 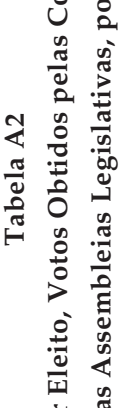 & $\begin{array}{l}\stackrel{0}{0} \\
\stackrel{0}{\pi} \\
: 0 \\
0 \\
0\end{array}$ & 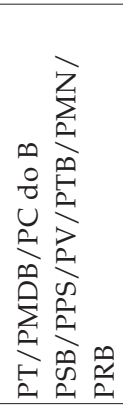 & 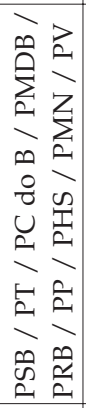 & 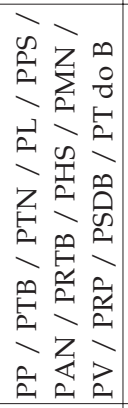 & 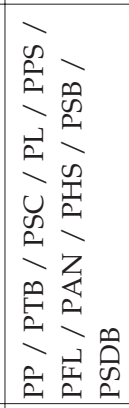 & 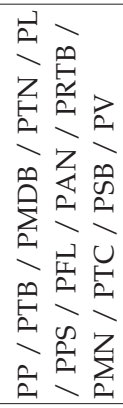 & 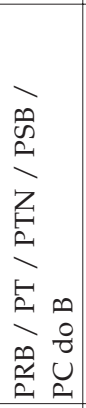 & 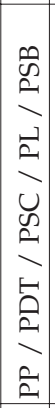 & 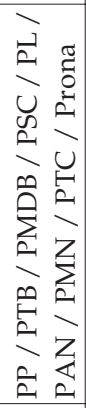 \\
\hline 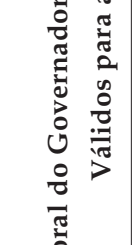 & 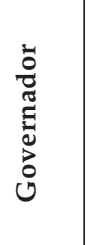 & 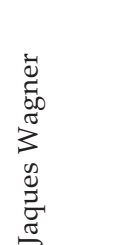 & 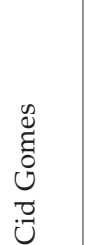 & 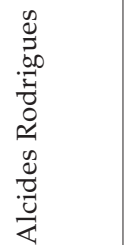 & 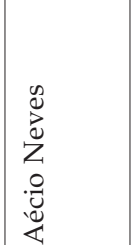 & 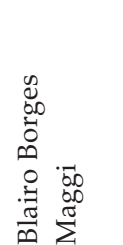 & 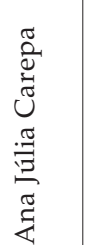 & 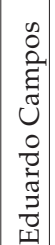 & $\begin{array}{l}\pi \\
\tilde{0} \\
0 \\
0 \\
0 \\
0.0 \\
0 \\
0 \\
0\end{array}$ \\
\hline 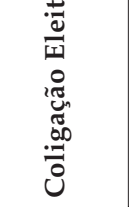 & 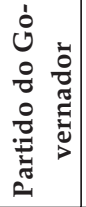 & $\vec{\omega}$ & की & $\hat{\mathrm{a}}$ & مै & $\omega_{1}^{\infty}$ & $\grave{L}$ & 点 & $\sum_{\hat{L}}^{\infty}$ \\
\hline 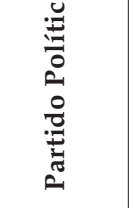 & & 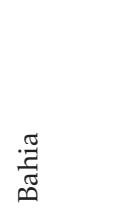 & $\tilde{\Xi}^{\tilde{J}}$ & $\begin{array}{l}: \frac{\pi}{8} \\
0 \\
0\end{array}$ & 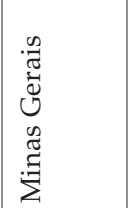 & \begin{tabular}{l}
0 \\
0 \\
0 \\
0 \\
0 \\
0 \\
0 \\
0 \\
0 \\
\multirow{0}{\pi}{} \\
$\Sigma$
\end{tabular} & ש & 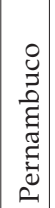 & 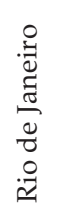 \\
\hline
\end{tabular}


Mônica Mata Machado de Castro, Fátima Anastasia e Felipe Nunes

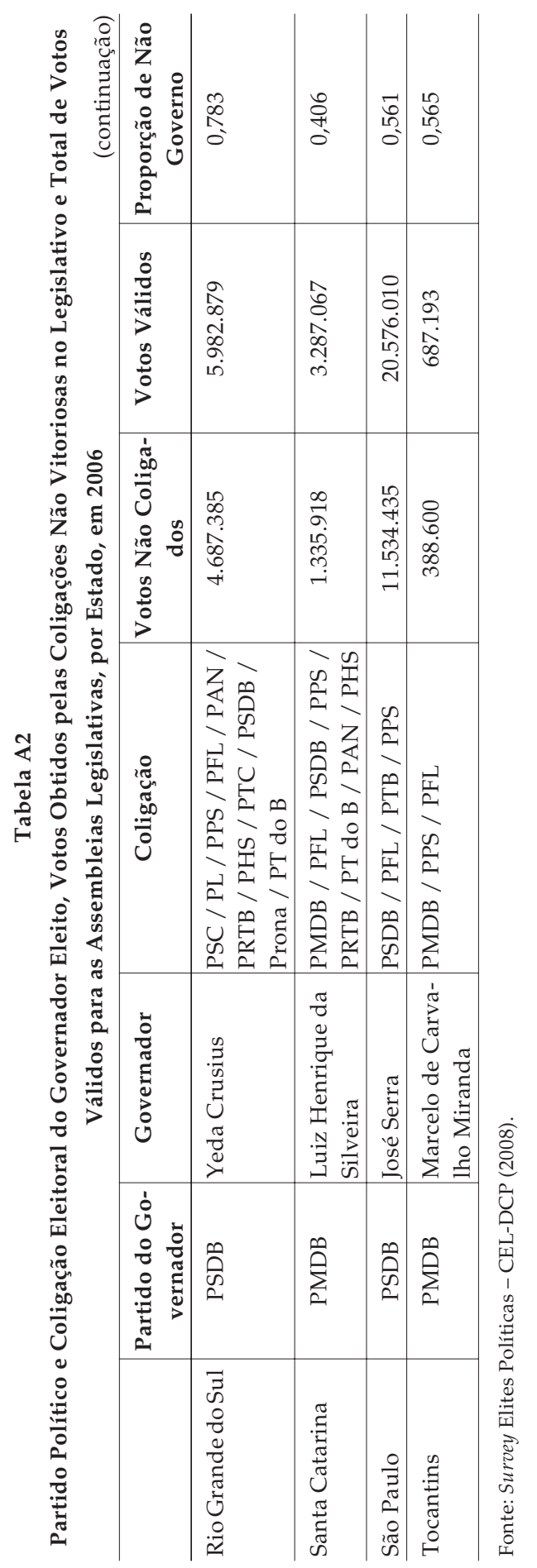


Determinantes do Comportamento Particularista de Legisladores...

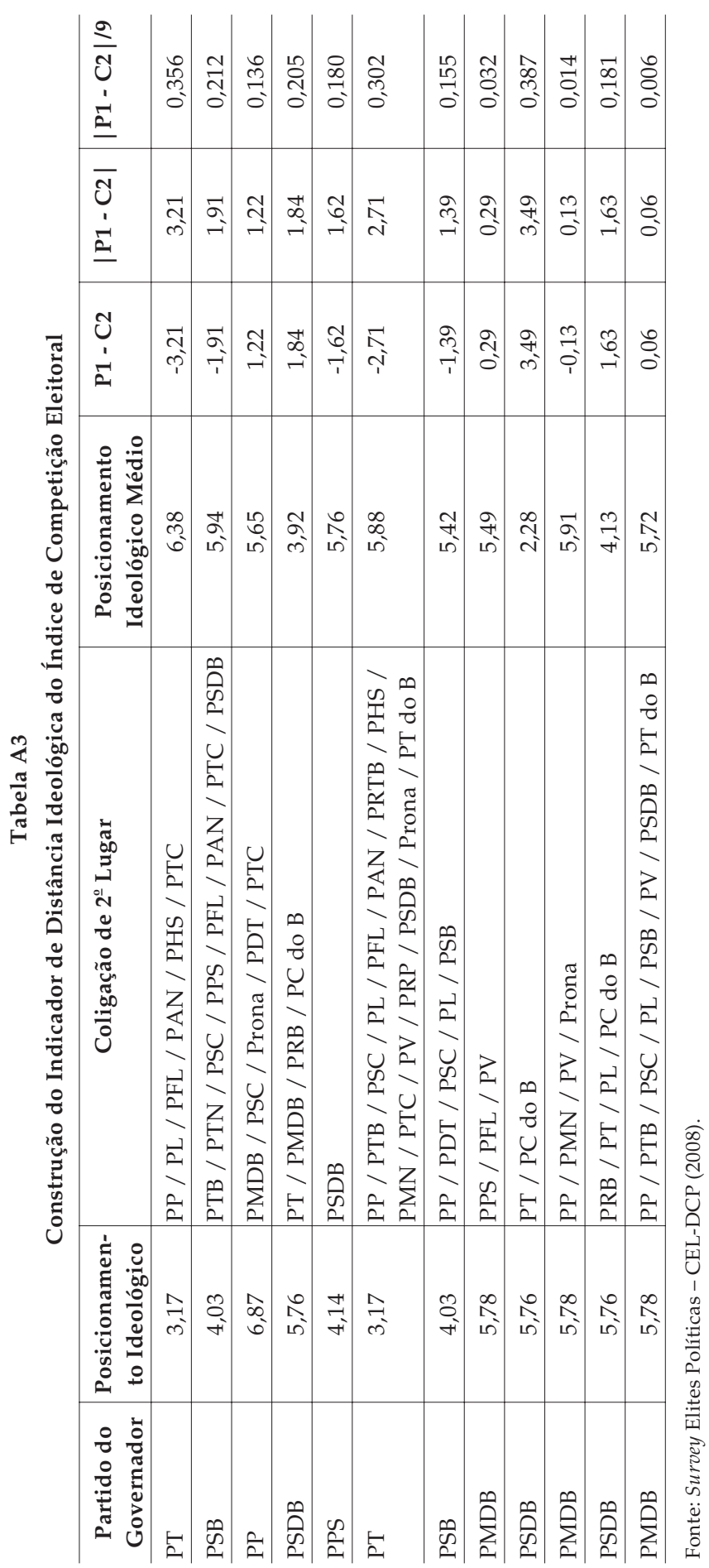


Mônica Mata Machado de Castro, Fátima Anastasia e Felipe Nunes

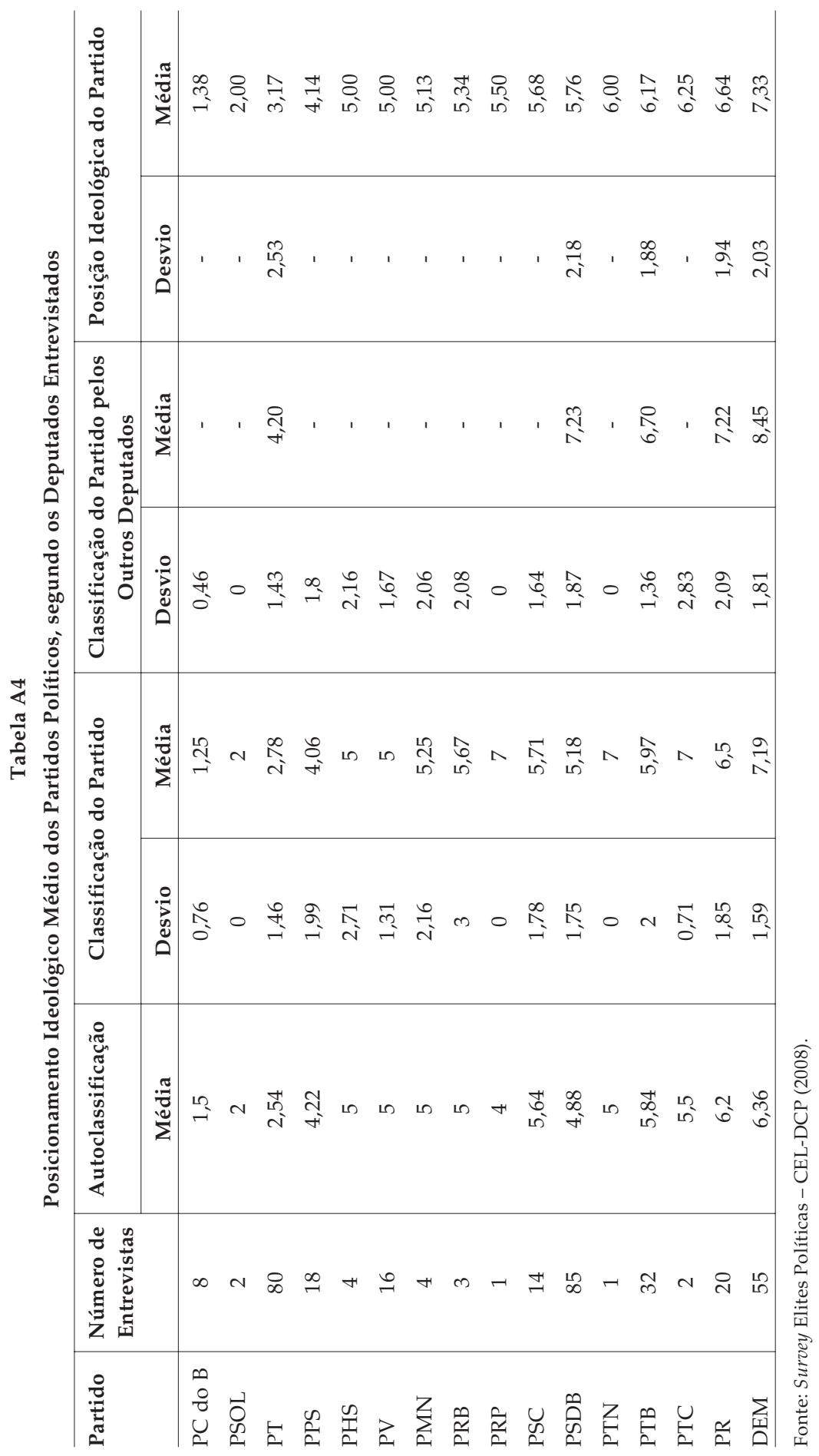


Determinantes do Comportamento Particularista de Legisladores...

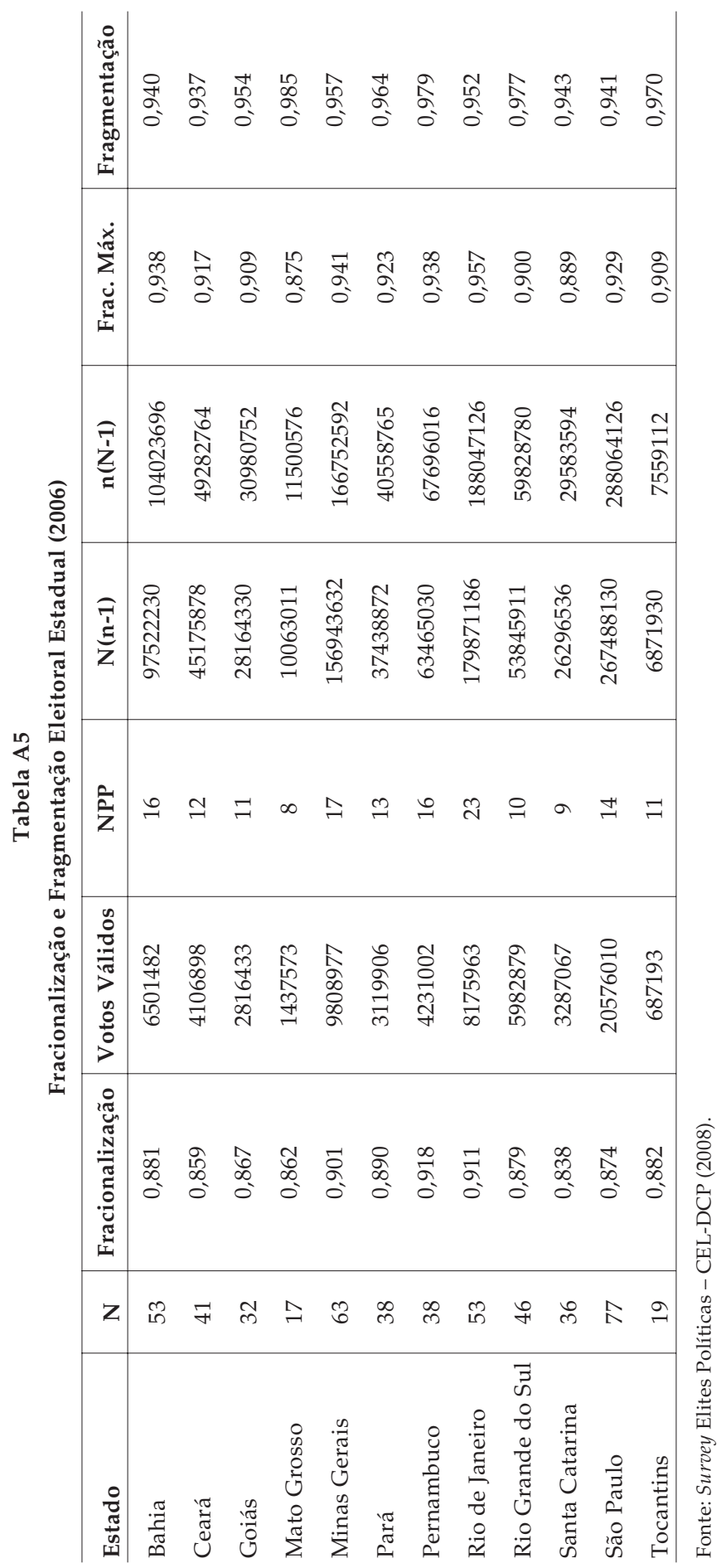


Tabela A6

Índice de Polarização Ideológica, por Estado

\begin{tabular}{l|c|c|c}
\hline Estado & Polarização Ideológica & PI - & PI - 1 /1,90 \\
\hline Goiás & 1,00 & 0,00 & 0,002 \\
Pará & 1,44 & 0,44 & 0,229 \\
Ceará & 1,56 & 0,56 & 0,295 \\
Tocantins & 1,57 & 0,57 & 0,302 \\
Rio de Janeiro & 1,68 & 0,68 & 0,355 \\
Santa Catarina & 1,77 & 0,77 & 0,407 \\
Mato Grosso & 1,79 & 0,79 & 0,414 \\
Minas Gerais & 1,82 & 0,82 & 0,431 \\
Pernambuco & 2,08 & 1,08 & 0,566 \\
São Paulo & 2,19 & 1,19 & 0,626 \\
Rio Grande do Sul & 2,29 & 1,29 & 0,678 \\
Bahia & 2,90 & 1,90 & 0,999 \\
\hline
\end{tabular}

Fonte: Survey Elites Políticas - CEL-DCP (2008).

Tabela A7

Fracionalização, Fracionalização Máxima e Fragmentação Parlamentar, por Estado (2006)

\begin{tabular}{l|c|c|c}
\hline Estado & F & F. Máx. & Fg. \\
\hline Bahia & 0,876 & 0,953 & 0,92 \\
Ceará & 0,825 & 0,937 & 0,881 \\
Goiás & 0,838 & 0,932 & 0,899 \\
Minas Gerais & 0,89 & 0,954 & 0,941 \\
Mato Grosso & 0,84 & 0,913 & 0,92 \\
Pará & 0,873 & 0,946 & 0,923 \\
Pernambuco & 0,9 & 0,957 & 0,94 \\
Rio de Janeiro & 0,9 & 0,97 & 0,927 \\
Rio Grande do Sul & 0,871 & 0,917 & 0,95 \\
Santa Catarina & 0,83 & 0,912 & 0,91 \\
São Paulo & 0,856 & 0,939 & 0,912 \\
Tocantins & 0,865 & 0,949 & 0,911 \\
\hline
\end{tabular}

Fonte: Survey Elites Políticas - CEL-DCP (2008). 


\section{ABSTRACT \\ Determinants of Particularist Behavior by Brazilian State Legislators}

This article focuses on the behavior of legislators in twelve States of Brazil. The aim was to analyze the effects produced by: 1) degree of electoral and legislative competition; 2) the ideological position of the State legislators' parties; 3 ) types of voter constituency; and 4) types of consistent supporters of State legislators in relation to the degree of their particularist behavior. The study drew on the results of a survey conducted in twelve States of Brazil, besides secondary data from the 2006 elections. The analysis used multiple linear regression models. The main observations related to: (a) the positive effect of regional interest representation and consistent regional supporters on particularist behavior and (b) the increased likelihood of particularist behavior among State legislators belonging to parties on the right of the political spectrum.

Key words: State legislatures; legislative behavior; party subsystems

\section{RÉSUMÉ}

Déterminants du comportement particulariste de législateurs des États brésiliens

Dans cet article, on examine le comportement des législateurs de douze États brésiliens. On cherche à détecter les effets produits par: 1) le degré de compétition électorale et législative; 2) la position idéologique des partis auxquels sont liés les députés étudiés; 3 ) les types de base électorale; et 4) la fermeté des défenseurs des députés des États, sur le niveau de leur comportement particulariste. On s'est servi d'un survey effectué dans 12 États de la Fédération et de données secondaires sur l'élection de 2006, dont l'analyse s'est basée sur des modèles de régression linéaire multiple. On a observé: a) l'effet positif de la représentation d'intérêts de type régional et des défenseurs fermes régionaux sur le comportement particulariste et b) la plus grande probabilité de comportement particulariste chez les députés liés à des partis plus à droite dans la gamme idéologique.

Mots-clé: législatifs des États; comportement législatif; sous-systèmes des partis 